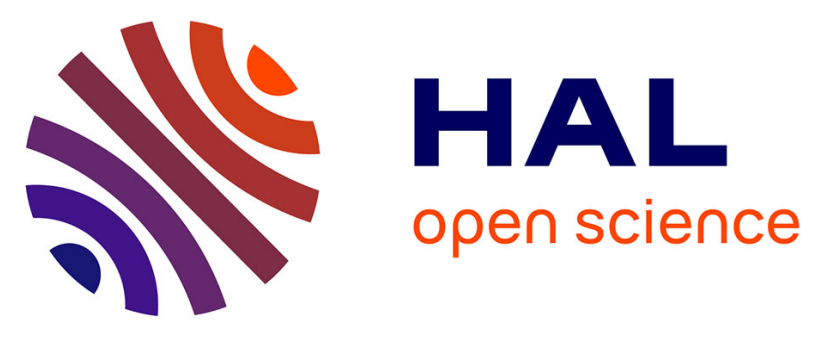

\title{
An interdisciplinary approach towards improved understanding of soil deformation during compaction
}

Thomas Keller, Mathieu Lamandé, S. Peth, M. Berli, Jean-Yves Delenne, W.

Baumgarten, W. Rabbel, Farhang Radjai, Jean Rajchenbach, A. P. S.

Selvadurai, et al.

\section{To cite this version:}

Thomas Keller, Mathieu Lamandé, S. Peth, M. Berli, Jean-Yves Delenne, et al.. An interdisciplinary approach towards improved understanding of soil deformation during compaction. Soil and Tillage Research, 2013, 128, pp.61-80. 10.1016/j.still.2012.10.004 . hal-00843268

\section{HAL Id: hal-00843268 \\ https://hal.science/hal-00843268}

Submitted on 16 Jan 2017

HAL is a multi-disciplinary open access archive for the deposit and dissemination of scientific research documents, whether they are published or not. The documents may come from teaching and research institutions in France or abroad, or from public or private research centers.
L'archive ouverte pluridisciplinaire HAL, est destinée au dépôt et à la diffusion de documents scientifiques de niveau recherche, publiés ou non, émanant des établissements d'enseignement et de recherche français ou étrangers, des laboratoires publics ou privés.

$$
\text { Copyright }
$$




\title{
Review
}

\section{An interdisciplinary approach towards improved understanding of soil deformation during compaction}

\author{
T. Keller ${ }^{\text {a,b,1,*, M. Lamandé c,1 }}$, S. Peth $^{\text {d,e }}$, M. Berli ${ }^{\text {f }}$, J.-Y. Delenne ${ }^{g}$, W. Baumgarten ${ }^{\text {d }}$, \\ W. Rabbel ${ }^{\text {h, }}$ F. Radjaï ${ }^{g}$, J. Rajchenbach $^{\mathrm{i}}$, A.P.S. Selvadurai ${ }^{\mathrm{j}}$, D. Or $^{\mathrm{k}}$ \\ ${ }^{a}$ Agroscope Reckenholz-Tänikon Research Station ART, Department of Natural Resources and Agriculture, Reckenholzstrasse 191, CH-8046 Zürich, Switzerland \\ ${ }^{\mathrm{b}}$ Swedish University of Agricultural Sciences, Department of Soil E' Environment, Box 7014, SE-75007 Uppsala, Sweden \\ ' Aarhus University, Department of Agroecology E' Environment, Research Centre Foulum, P.O. Box 50, DK-8830 Tjele, Denmark \\ ${ }^{\mathrm{d}}$ Christian-Albrechts-University Kiel, Institute for Plant Nutrition and Soil Science, Hermann-Rodewaldstrasse 2, D-24118 Kiel, Germany \\ e University of Kassel, Faculty 11, Organic Agricultural Sciences, Group of Soil Science, Nordbahnhofstrasse 1a, D-37213 Witzenhausen, Germany \\ ${ }^{\mathrm{f}}$ Desert Research Institute, Division of Hydrologic Sciences, 755 E. Flamingo Road, Las Vegas, NV, USA \\ ${ }^{\mathrm{g}}$ Université Montpellier 2, Physics and Mechanics of Granular Media, Cc 048, F-34095 Montpellier Cedex 5, France

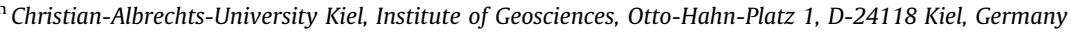 \\ ${ }^{\mathrm{i}}$ Université de Nice, Laboratoire de Physique de la Matière Condensée, 28 Avenue Valrose, F-06108 Nice Cedex 2, France \\ ${ }^{\mathrm{j}}$ McGill University, Department of Civil Engineering and Applied Mechanics, 817 Sherbrooke Street West, Montréal, QC, H3A 2K6, Canada \\ ${ }^{\mathrm{k}}$ Swiss Federal Institute of Technology, Soil and Terrestrial Environmental Physics, Universitätstrasse 16, CH-8092 Zürich, Switzerland
}

Soil compaction not only reduces available pore volume in which fluids are stored, but it alters the arrangement of soil constituents and pore geometry, thereby adversely impacting fluid transport and a range of soil ecological functions. Quantitative understanding of stress transmission and deformation processes in arable soils remains limited. Yet such knowledge is essential for better predictions of effects of soil management practices such as agricultural field traffic on soil functioning. Concepts and theory used in agricultural soil mechanics (soil compaction and soil tillage) are often adopted from conventional soil mechanics (e.g. foundation engineering). However, in contrast with standard geotechnical applications, undesired stresses applied by agricultural tyres/tracks are highly dynamic and last for very short times. Moreover, arable soils are typically unsaturated and contain important secondary structures (e.g. aggregates), factors important for affecting their soil mechanical behaviour. Mechanical processes in porous media are not only of concern in soil mechanics, but also in other fields including geophysics and granular material science. Despite similarity of basic mechanical processes, theoretical frameworks often differ and reflect disciplinary focus. We review concepts from different but complementary fields concerned with porous media mechanics and highlight opportunities for synergistic advances in understanding deformation and compaction of arable soils. We highlight the important role of technological advances in non-destructive measurement methods at pore (X-ray tomography) and soil profile (seismic) scales that not only offer new insights into soil architecture and enable visualization of soil deformation, but are becoming instrumental in the development and validation of new soil compaction models. The integration of concepts underlying dynamic processes that modify soil pore spaces and bulk properties will improve the understanding of how soil management affect vital soil mechanical, hydraulic and ecological functions supporting plant growth.
Keywords:

Soil compaction

Continuum mechanics

Granular media

Seismic methods

Modelling

X-ray computed tomography

\section{Contents}

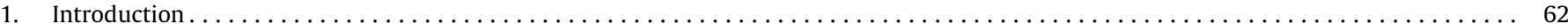

2. Deformation of porous media: theory, approaches and applications of different research fields $\ldots \ldots \ldots \ldots$

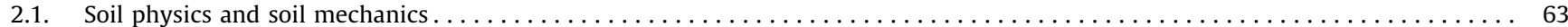

2.1.1. Soil physics and soil mechanics - similar subject, different approaches $\ldots \ldots \ldots 6$

\footnotetext{
* Corresponding author. Tel.: +41 4437776 05; fax: +41 443777201.

E-mail addresses: Thomas.Keller@slu.se, thomas.keller@art.admin.ch (T. Keller).

1 These authors contributed equally to this work.
} 


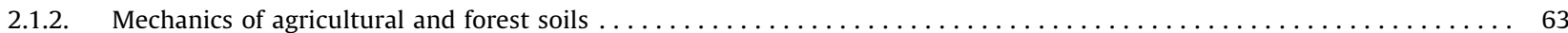

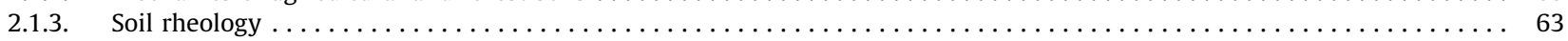

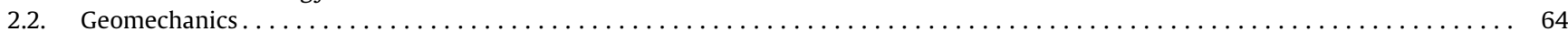

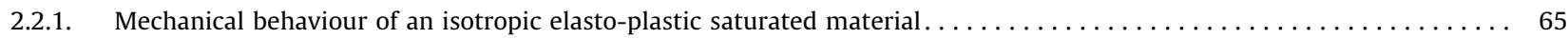

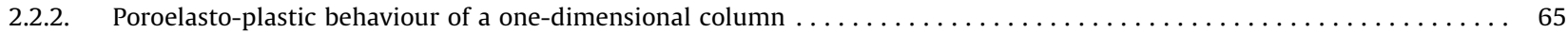

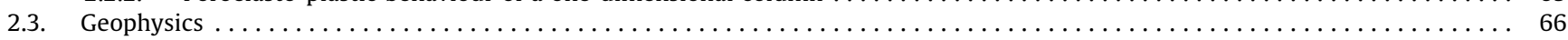

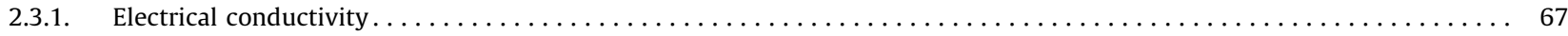

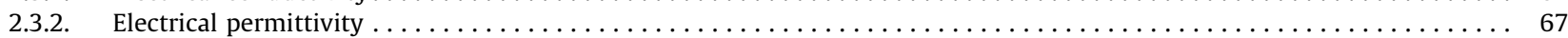

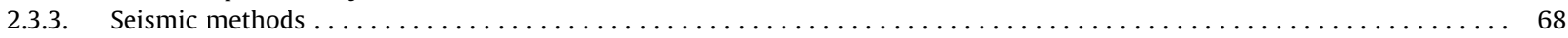

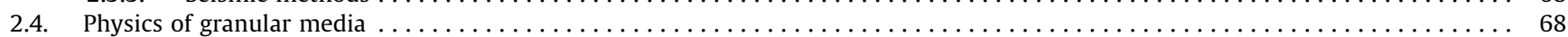

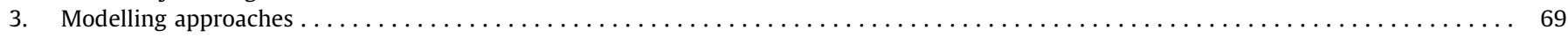

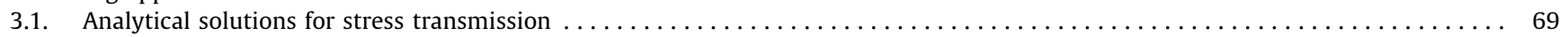

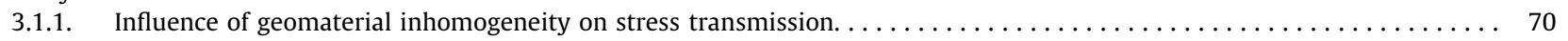

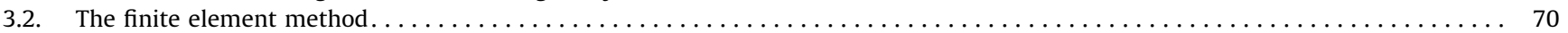

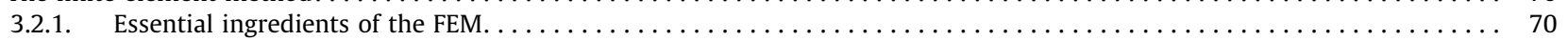

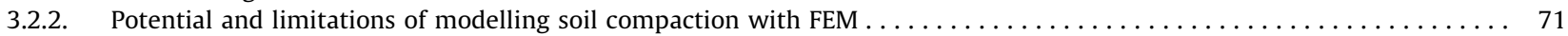

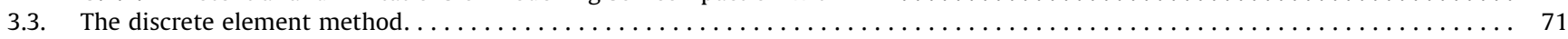

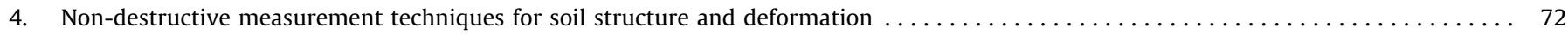

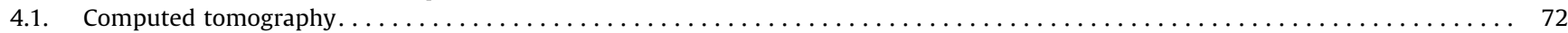

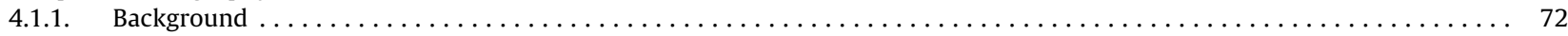

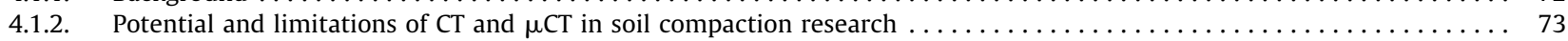

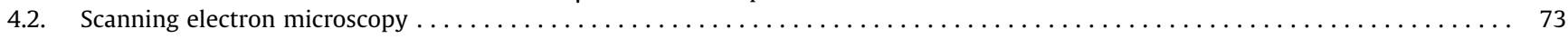

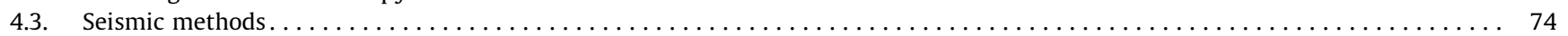

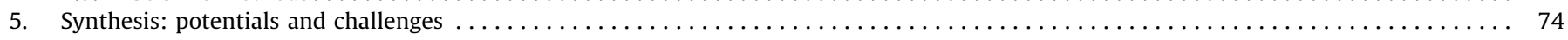

5.1. Scale-dependent soil structural organization and how it influences soil strength, stress transmission and soil deformation ....... 74

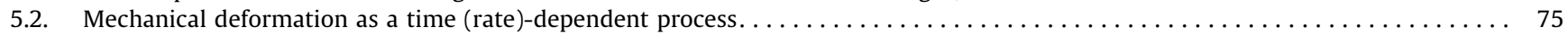

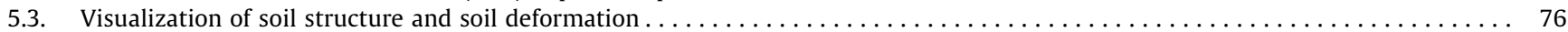

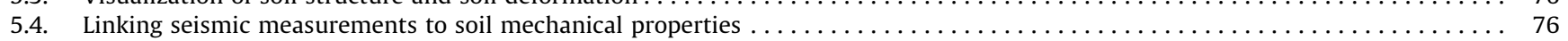

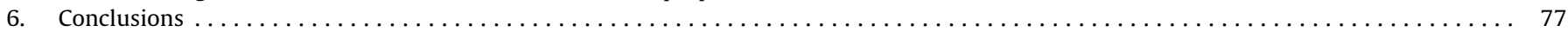

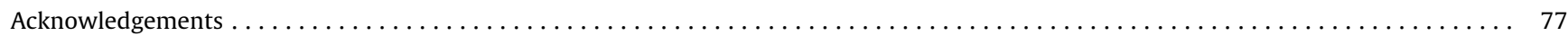

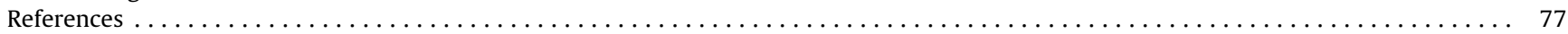

\section{Introduction}

Soil compaction (i.e. reduction of soil porosity) is one of the main threats to sustaining soil quality in Europe (COM, 2006). A range of important ecological functions is affected when soil is compacted (e.g. van Ouwerkerk and Soane, 1995; Alaoui et al., 2011): compaction reduces saturated hydraulic conductivity and thus triggers surface runoff and soil erosion by water; it may induce preferential flow in macropores, and hence facilitates transport of colloid-adsorbed nutrients and pesticides to deeper horizons and water bodies; compaction reduces soil aeration, and hence reduces root growth and induces loss of nitrogen and production of greenhouse gases through denitrification by anaerobic processes. Consequently, soil compaction is one of the causes of a number of environmental and agronomic problems (flooding, erosion, leaching of chemicals to water bodies, crop yield losses) resulting in significant economic damage to the society and agriculture.

Our understanding of deformation processes in arable soil is still limited. One reason might be that in soil compaction research, the major focus has been on the agronomic (and, more recently, environmental) impacts of compaction, rather than on the soil deformation process itself. That is, the externally applied mechanical stress (e.g. by agricultural machinery) is related to (physical) soil functions or crop response. While such studies are undoubtedly valuable, they do not directly add to the knowledge of the soil compaction process itself. In order to understand the impacts of soil compaction on soil functions (reaction), knowledge of the soil deformation process (cause) is needed.

Soil deformation is the response of a soil to an applied stress, which could be either mechanical or hydraulic. Stress and deformation are coupled processes: soil deformation is a function of soil stress and soil strength, and the propagation of stress in soil is a function of soil strength and soil deformation.
A better mechanistic understanding of stress transmission in structured soil and the deformation behaviour of unsaturated soil will improve models for prediction of soil compaction. Such models are needed to develop strategies and guidelines for the prevention of soil compaction. Furthermore, improved understanding of the soil deformation processes will promote better predictions of the impact of soil management practices on physical soil functions and their effect on processes listed above.

Concepts and theory used in agricultural soil mechanics (soil compaction and soil tillage) are generally adopted from conventional soil mechanics (e.g. foundation engineering). Examples are analytical solutions for stress propagation in soil based on the works of Boussinesq (1885) and Fröhlich (1934), soil compressive strength characterized by the precompression stress that is based on Casagrande (1936), or models for predicting draught force of tillage implements that are based on early studies of Coulomb (1776) and Rankine (1858).

Nevertheless, agricultural soil mechanics differs from geotechnical applications in a range of aspects, most notably: (i) stresses applied by running tyres, tracks, and tillage implements are dynamic and the loading time is very short $(\sim 1 \mathrm{~s})$; (ii) agricultural soil is typically unsaturated, which makes interactions between hydraulics and mechanics very important, but also complex (Horn et al., 1998; Richards and Peth, 2009); and (iii) arable soil is structured with compound particles of different sizes and shapes and a network of voids with various morphologies and orientation (e.g. biopores, shear fractures, desiccation cracks). Consequently, models for calculating stress transmission and deformation in arable soil that are based on foundation engineering concepts suffer from insufficient knowledge of soil structure (fabric) and soil moisture effects on stress transmission, and poor characterization of soil mechanical properties relevant for short-term dynamic loading occurring on agricultural soils (Keller and Lamandé, 2010). 
Stress transmission and deformation processes in porous media are not only a topic in soil mechanics and geomechanics, but also in other research fields including geophysics, granular material science, and snow/avalanche research. Although dealing with similar processes, the theoretical frameworks used are often research-field specific. We believe that a combination of different approaches could advance our understanding of deformation processes in arable soils. An International Exploratory Workshop held during the autumn of 2010 at the Agroscope Research Station ART in Zürich (Switzerland) brought together scientists dealing with porous media mechanics from different perspectives ranging from classical soil physics including soil mechanics to geomechanics, geophysics, and physics of granular mixtures. The aim of the workshop was to introduce and jointly discuss theoretical frameworks and modelling approaches applied in different fields to porous media mechanics, and to explore possible new approaches to quantitative description of soil compaction.

The primary objectives of this paper were to: (i) review theory, modelling approaches and non-destructive measurement techniques applied in different research fields that deal with deformation of porous media, and (ii) delineate new approaches and pathways for improving the theoretical and experimental basis for modern soil compaction research.

\section{Deformation of porous media: theory, approaches and applications of different research fields}

Several disciplines (such as soil mechanics, geotechnics, geophysics, granular material science, etc.) deal with deformation processes in porous media. However, the theoretical approaches that describe the physical nature of deformation and the frameworks to solve applications differ between disciplines. This can be attributed to differences in material properties, loading characteristics and boundary conditions of the relevant specific processes. Nevertheless, some of the distinctions may simply be due to historical reasons.

\subsection{Soil physics and soil mechanics}

\subsubsection{Soil physics and soil mechanics - similar subject, different approaches}

In one of the earliest textbooks on soil physics, Baver (1940) defines soil physical properties as: "the mechanical behaviour of the soil mass". Around the same time, Terzaghi (1943) defines soil mechanics as: "the application of the laws of mechanics and hydraulics to engineering problems dealing with sediments and other unconsolidated accumulations of solid particles produced by the mechanical and chemical disintegration of rocks". Although the two definitions address closely related topics, soil physics and mechanics evolved parallel with little interactions for a good part of the 20th century. What happened?

Soil physics was developed within the disciplines of agronomy and forestry, driven by the need for land reclamation, irrigation, and drainage as well as related topics such as groundwater recharge, salinization and flood control. Soil physics primarily focused on quantifying hydraulic properties and processes of partially saturated soils. In contrast, starting from the early work of Coulomb (1776), Rankine (1857) and Boussinesq (1885), soil mechanics was addressing foundation and slope stability problems related to fortification, road and dam construction. As an engineering discipline, soil mechanics developed strongly in the early 20th century with Fillunger (1913), Terzaghi $(1923,1925)$ and Fröhlich (1934). With the development of more advanced mechanical models for soil such as Critical State Soil Mechanics (CSSM) (Roscoe et al., 1958; Schofield and Wroth, 1968) and extending from saturated to unsaturated soils (e.g. Bishop, 1959;
Bailey and VandenBerg, 1968; Alonso et al., 1990), frameworks became available that explicitly consider changes in void ratio (or porosity) as a function of applied stress as well as the impact of moisture conditions on the mechanical behaviour of soil.

However, it is clear that fluid transport through soil (primary focus of soil physics) and stability and deformation processes (main focus of soil mechanics) cannot be separated from each other, because any deformation results in a change in fluid transport properties, while any hydraulic process influences the deformation behaviour of soil. The emerging need to solve environmental issues related to deformable soils (e.g. contaminant transport through engineered clay liners, geologic sequestration of greenhouse gases, impact of vehicle traffic on soil hydraulic properties) finally brought soil physics and soil mechanics closer together (Vulliet et al., 2002). The protection of agricultural and forest soils from compaction is one of these needs.

\subsubsection{Mechanics of agricultural and forest soils}

Since its beginning in the 19th century, the mechanics of agricultural and forest soils was linked to problems related to trafficability and soil-vehicle interactions. Soil compaction did not receive much attention before increased mechanization of post World War II agriculture sparked concerns about decreasing soil fertility due to vehicle-induced compaction. Although the focus of attention moved away from the problem of pure trafficability towards preserving soil fertility, military needs remained the main driver to study soil-vehicle interaction until the late 1960s (Bekker, 1956, 1969).

To describe and predict soil compaction due to vehicle traffic, the work by Söhne $(1951,1953,1958)$ was certainly pioneering and addressed the main issues of modern day compaction research such as stress distribution at the tyre-soil interface, stress transfer into the soil as well as impact of these stresses on the degree of soil compaction. Both Bekker (1956) and Söhne $(1951,1953)$ employed mechanical concepts developed by Rankine (1857), Boussinesq (1885), Terzaghi $(1925,1943)$ and Fröhlich (1934) to derive their stress-strain models for soils under vehicular traffic. The strength of these models lay in their simplicity, which makes them hugely popular to this day for applications in agriculture and forestry.

With the introduction of concepts like CSSM and unsaturated soil mechanics, more advanced frameworks became available to describe soil deformation. Although some of these models were adopted to describe the mechanics of agricultural soils as early as in the 1960s (e.g. Bailey and VandenBerg, 1968) and have been further developed ever since (e.g. Hettiaratchi, 1987; Gräsle et al., 1995; Kirby, 1994; O'Sullivan and Robertson, 1996), no comprehensive mechanical theory for agricultural and forest soils is currently available.

One reason is that agricultural and forest soils feature various forms of secondary structure that affect the mechanical as well as hydraulic properties of the soil (e.g. Hartge and Sommer, 1980; Horn, 1993) but are hard to quantify. Only recently, advances in imaging using X-ray (micro-) tomography have allowed nondestructive visualization of the soil structure, a key step towards quantifying the impact of structure on soil hydraulic and mechanical properties. Driven by the increasing possibilities of soil structure visualization, structure-based micro-scale soil mechanics models were developed, which allow the consideration of the interaction of mechanics and hydraulics of the soil at the pore scale (e.g. Or and Ghezzehei, 2002; Eggers et al., 2006).

\subsubsection{Soil rheology}

The extent of soil compaction and subsequent structural recovery are greatly influenced by loading and deformation rates that in turn are determined by soil rheological properties. In contrast with motion and mechanics of rigid bodies, rheology deals 
with relative motions of the parts of a body relatively to each another (Reiner, 1960). Under the action of a force, a body may deform elastically (deformation is fully recoverable when the force is removed), plastically (permanent deformation even when the force is removed), or the material may flow at a certain rate (continuous deformation without limit under the action of a force). Reiner (1960) defines "rheology in the narrower sense" as the science that deals with the deformation and flow of materials that are classified between the extremes of solid (Euclid-solid: rigid body; and Hooke-solid: elastic body) and liquid (Newtonian liquid: ideal viscous liquid; and Pascalian liquid: inviscid liquid).

We may distinguish macro-rheology from micro-rheology (Reiner, 1960): macro-rheology considers materials as homogeneous, whereas micro-rheology considers material structure. Macro-rheology is partly treated within "classical" (continuum) soil mechanics, dealing primarily with strain and stress (e.g. stress-strain curves obtained from uniaxial compression tests, triaxial tests or shear tests). Nevertheless, mechanical behaviour of soil is also dependent upon strain and stress rates, which have received little attention in classical soil mechanics (perhaps due to preoccupation with foundations and static structures). Microrheology has two main tasks (Reiner, 1960): it aims at either (i) obtaining a picture of the structure of the material giving rise to measured flow curves, or (ii) at explaining the rheological behaviour of a complex material from the known rheological behaviour of its constituents.

In practice, soil rheology deals with dynamic soil deformation processes that consider soil structure, rates of load application and resulting deformation. According to Or (1996), traditional stressstrain approaches fail to capture salient features of soil structure dynamics because these approaches (i) are based on equilibrium state while deformation in agricultural soils are dynamic processes that rarely reach equilibrium, and (ii) often describe bulk volume changes only but cannot describe the evolution of the soil structure at the pore scale that is crucial for flow and transport processes central to hydrological and agronomic applications.

Recent developments in soil rheology address the two main tasks of micro-rheology as described by Reiner (1960). The work of Markgraf, Horn and co-workers (see Markgraf et al., 2006) aims at characterizing the structure of soil from observed rheological test curves. Or and co-workers (see Or and Ghezzehei, 2002) developed models for soil structure dynamics at the pore scale based on rheological properties.

Ghezzehei and Or (2000, 2001) developed models for soil aggregate deformation and coalescence due to wetting-drying cycles as well as due to external static and cyclic stresses. These models were further extended to include closure of isolated pores (Ghezzehei and Or, 2003; Berli and Or, 2006; Berli et al., 2006), which can then be used, for example, to investigate the evolution of hydraulic conductivity upon compression (Eggers et al., 2006; Berli et al., 2008). The approaches are based on (i) geometrical representations of aggregates, pore space and liquid menisci, (ii) energy considerations, and (iii) rheological properties of unsaturated soil.

It was shown that soil under steady state stress behaves as a viscoplastic material that can be described as a Bingham body (Vyalov, 1986; Ghezzehei and Or, 2000, 2001) as illustrated in Fig. 1a, which in general terms can be given as (Reiner, 1960; Or and Ghezzehei, 2002):

$\dot{\gamma}=\left\{\begin{array}{cc}0 & \tau<\tau_{y} \\ \left(\tau-\tau_{y}\right) / \eta_{p l} & \tau \geq \tau_{y}\end{array}\right.$

where $\tau$ is the shear stress, $\tau_{y}$ is the yield stress, $\dot{\gamma}$ is the strain rate, and $\eta_{p l}$ is the plastic viscosity. It is seen from Fig. 1 that the rheological properties $\tau_{y}$ and $\eta_{p l}$ (the inverse slope of the straight line of the Bingham model) are functions of soil water content: both $\tau_{y}$ and $\eta_{p l}$ decrease with increasing water content.

Energy generally appears under three forms in rheological phenomena (Reiner, 1960): kinematic energy, elastic (potential) energy, and dissipated (thermal) energy. Elastic energy is stored (conserved) during deformation and fully recovered upon stress release, while energy is dissipated during viscous flow is permanent (if elastic energy is not permanently conserved but dissipates with time, this is referred to as dissipation by relaxation.) Hence, total strain can be divided into an elastic and a viscous component. The ratio of elastic to viscous strain is dependent on the stress rate and the loading time, as shown by Ghezzehei and Or (2001): the shorter the loading rate, the larger the elastic strain and the smaller the viscous (permanent) component of the total strain. Consequently, storage of elastic energy (and therefore elastic strain) is of importance especially during deformation under cyclic or transient stresses as occur e.g. during the passage of agricultural machinery. The behaviour of the soil can then be described as "visco-elastic" (Ghezzehei and Or, 2001). It is convenient to express the visco-elastic properties in a complex plane system. The shear stress, $\tau$, and strain, $\gamma$, can be related by (Ghezzehei and Or, 2001):

$\tau=G * \gamma$

where $G^{*}$ is the complex shear modulus; similarly, $\tau$ and strain rate, $\dot{\gamma}$, can be related by

$\tau=\eta^{*} \dot{\gamma}$

where $\eta^{*}$ is the complex viscosity. The real components of $G^{*}$ and $\eta^{*}$ indicate the storage (elastic) shear modulus, $G^{\prime}$, and elastic viscosity, $\eta^{\prime}$, respectively, while the imaginary components of $\mathrm{G}^{*}$ and $\eta^{*}$ indicate the loss (viscous) shear modulus, $G^{\prime \prime}$, and loss viscosity, $\eta^{\prime \prime}$, respectively (Ghezzehei and Or, 2001). The relative proportion of the elastic and viscous component can be obtained from the phase shift angle (also termed the mechanical loss angle), $\delta$, that describes the delay in strain (peak) due to an applied stress (peak) as a result of the time dependence of viscous strain ( $\delta=0$ for ideal elastic material; $\delta=\pi / 2$ for ideal viscous material) (Ghezzehei and Or, 2001).

Markgraf et al. (2006) measured the stress-strain rate relationship in a rotational rheometer in order to derive $G^{\prime}, G^{\prime \prime}$ and the "loss factor" $\tan \delta\left(=G^{\prime \prime} \mid G^{\prime}\right)$, as well as the linear visco-elastic (LVE) deformation range and the deformation limiting value, $\gamma_{\mathrm{L}}$. Three phases of material behaviour can be identified (Markgraf et al., 2006; Markgraf, 2011), as illustrated in Fig. 2. In phase I (initial or plateau phase) $G^{\prime}>G^{\prime \prime}$, a quasi-elastic behaviour can be observed. The quasielastic stage is defined by the LVE range and the deriving deformation limit $\gamma_{\mathrm{L}}$. At this stage of low strain, a full recovery of the microstructure can be assumed. In phase II.1, a stage of preyielding occurs due to higher strain; soil particles are re-oriented, microstructural stability is given, but decreasing. At the end of phase II.2, an intersection of $G^{\prime}$ and $G^{\prime \prime}$ indicates the yield-point. In comparison, the intersection of $\tan \delta$ with the $\tan \delta=1$-line also indicates a complete loss of stability of the soil microstructure (Markgraf and Horn, 2009). By calculating the integral $z$ (Fig. 2b), the structural strength, which includes quasi-elasticity and pre-yielding behaviour, can be quantified. Hence, phase III defines the final stage of structural collapse, $G^{\prime}<G^{\prime \prime}$; a viscous character predominates, and substances are creeping or flowing.

\subsection{Geomechanics}

Applications of classical continuum mechanics range from the use of elasticity theory (e.g. Davis and Selvadurai, 1996) to micromechanical approaches based on particulate mechanics 

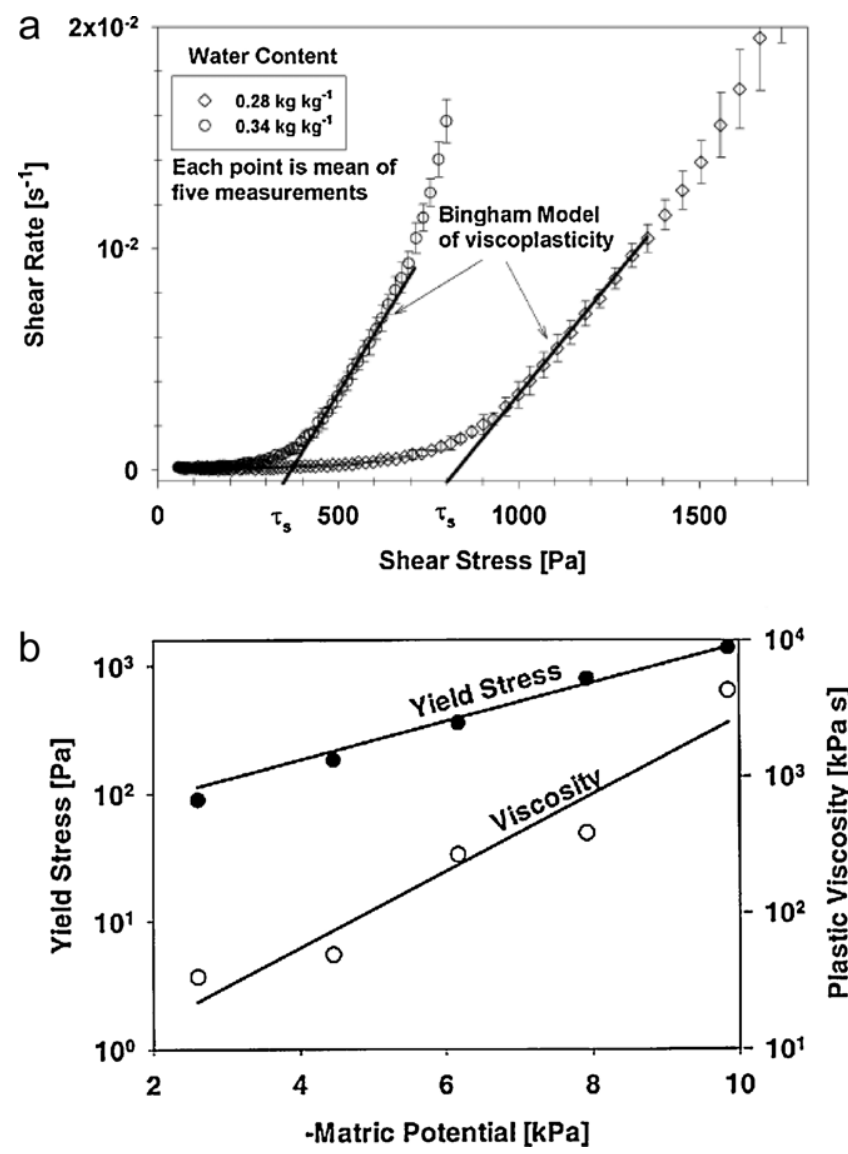

Fig. 1. (a) Example of a strain rate versus stress curve (silt loam at two different water contents) (from Or and Ghezzehei, 2002). (b) Coefficient of plastic viscosity and yield stress as functions of soil matric potential for the same soil. From Ghezzehei and Or (2000).

(e.g. Misra and Huang, 2009; see also Section 2.4). The subject of geomechanics has made important advances in terms of describing the mechanics of porous geomaterials by taking into consideration their multi-phase nature, especially pertaining to the coupled behaviour involving fluid flow through the pore space, mechanical deformations (both reversible and irreversible) and thermal deformations of the separate phases (e.g. Desai and Siriwardane, 1984; Selvadurai and Nguyen, 1995; Pietruszczak, 2010).

The objective of Section 2.2 is to examine two problems, which demonstrate the ability of advanced theories of continuum poromechanics (continuum mechanics that studies the behaviour of fluid-saturated porous media) to provide explanations of soil compaction phenomena. The compaction of an array of soil aggregates ( $c f$. Fig. 3 ) is a more complex problem that cannot be obtained conveniently with continuum mechanics as discussed in Sections 2.1.3 and 5.1.

\subsubsection{Mechanical behaviour of an isotropic elasto-plastic saturated material}

The mechanical behaviour of a fluid-saturated porous medium undergoing infinitesimal elastic strains was first developed by Biot (1941), taking into consideration Darcy's law to describe the flow of the fluid through the pore space and Hookean elastic behaviour of the porous skeleton to describe deformations. The basic constitutive equations governing the mechanical and fluid transport behaviour of an isotropic poroelastic medium consisting of non-deformable solid matter, which is saturated with an incompressible fluid, can be written in the forms

$v_{f}=-\frac{\mathbf{K}_{\mathrm{s}}}{\mu} \nabla p$

$\boldsymbol{\sigma}=G(\nabla \mathbf{u}+\mathbf{u} \nabla)+(\lambda \nabla \mathbf{u}) \mathbf{I}+p \mathbf{I}$

where $\boldsymbol{\sigma}$ is the total stress tensor, $\mathbf{u}$ is the displacement vector of the skeletal phase, $\mathbf{v}_{f}$ refers to the velocities of the fluid, $p$ is the fluid pressure in the pore space, $\mathbf{K}_{\mathrm{s}}$ is the saturated permeability matrix, $G$ and $\lambda$ are Lamé elastic constants of the porous skeleton, $\mu$ is the dynamic viscosity of water, $\nabla$ is the gradient operator, and $\mathbf{I}$ is the unit matrix. In Eq. (4) the velocity of the porous matrix is neglected.

In extending the studies to include poroelasto-plasticity effects, we need to select an appropriate constitutive response for saturated clay-type materials. A variety of constitutive relations have been proposed in the literature. For the purpose of illustration, an elasto-plastic skeletal response of the Modified Cam Clay type (e.g. Desai and Siriwardane, 1984; Davis and Selvadurai, 2002) is presented here. Attention is restricted to an isotropic elasto-plastic material defined by the yield function

$(\tilde{\sigma}-a)^{2}+(q / M)^{2}-a^{2}=0$

where $q$ is the von Mises stress, $a$ is the radius of the yield surface, $\tilde{\sigma}$ is the mean effective stress, $M$ is the slope of the critical state line and these are defined by

$q=\sqrt{\left.3 \tilde{s}_{i j} \tilde{s}_{i j}\right|_{2} ;} \quad \tilde{\sigma}=-\left(\tilde{\sigma}_{k k} / 3\right) ; \quad \tilde{s}_{i j}=\tilde{\sigma}_{i j}+\tilde{\sigma} \delta_{i j}$

The hardening rule is defined by

$\tilde{\sigma}=\tilde{\sigma}\left(\varepsilon_{k k}^{p l}\right)=\tilde{\sigma}_{c}^{0}+\tilde{\sigma}_{c}\left(\varepsilon_{k k}^{p l}\right)$

and the incremental plastic strains are defined by an associated flow rule of the type

$d \varepsilon_{i j}^{p l}=d \lambda \frac{\partial G}{\partial \tilde{\sigma}_{i j}} ; G=\sqrt{\left(\tilde{\sigma}-\frac{\tilde{\sigma}_{c}^{o}}{2}-\frac{\tilde{\sigma}_{c}\left(\varepsilon_{k k}^{p l}\right)}{2}\right)^{2}+\left(\frac{q}{M}\right)^{2}}$

where the hardening rule takes the form

$\tilde{\sigma}_{c}=\tilde{\sigma}_{c}\left(\varepsilon_{k k}^{p l}\right)=H\left(-\varepsilon_{k k}^{p l}\right)$

and $H$ is a positive constant. In addition to the elasto-plastic constitutive response for the porous skeleton, it is assumed that the fluid flow through the porous skeleton remains unchanged during yield and subsequent hardening of the porous skeleton. However, it is recognized that deformation changes the permeability of geomaterials (e.g. Berli et al., 2008). Furthermore, the compaction process can induce stratifications at the macro-level of the fabric that can give rise to transversely isotropic properties in all mechanical and transport phenomena.

\subsubsection{Poroelasto-plastic behaviour of a one-dimensional column}

For the purpose of illustration, we consider the problem of a one-dimensional column, which is saturated with an incompressible fluid and the porous skeleton can possess an elasto-plastic constitutive response described by Eqs. (6-10). The surface of the one-dimensional column is subjected to a quasi-static normal traction or in a cyclic loading-unloading mode in a timedependent fashion as shown in Fig. 4a. The upper surface of the column is maintained at zero pore fluid pressure. The constitutive models are implemented in a general purpose computational multiphysics code and the initial boundary value problems are analysed via a finite element technique.

Fig. 4b shows the response of the poroelasto-plastic soil skeleton model. Unlike in poroelasticity (not shown), the cyclic 
(a)

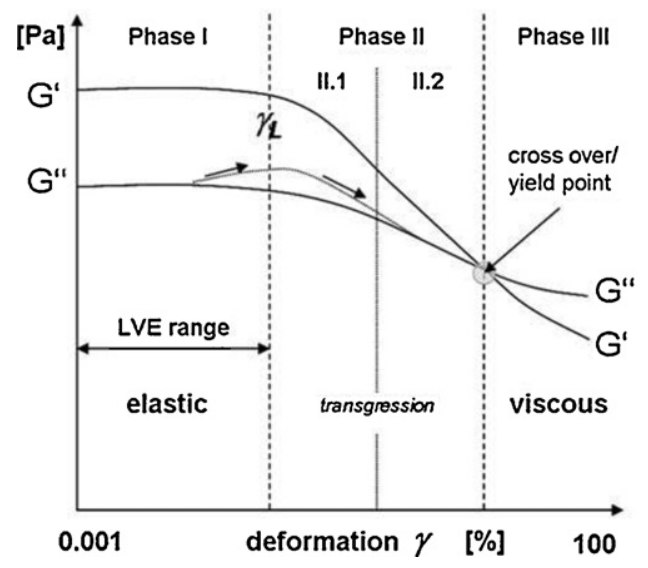

(b)

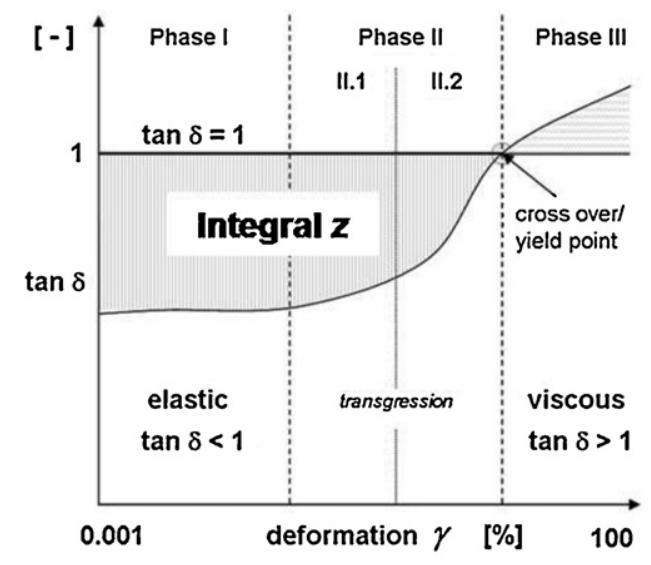

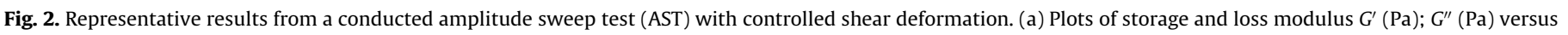

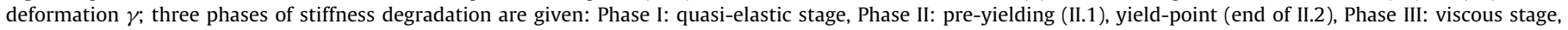

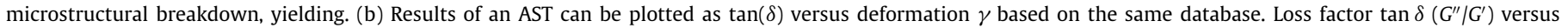
deformation $\gamma$; if $\tan \delta=1$ is crossed, a viscous character is given. By calculating integral $z$, stiffness (rigidity; elasticity) can be quantified.

From Markgraf (2011).

loading results in surface displacement patterns that exhibit a permanent deformation. Furthermore, the number of cycles of loading can influence the permanent deformation (Horn et al., 2003). The monotonic application of a peak load results in the greatest permanent strain. The pore pressure history is influenced by the load cycling (Fig. 4c). The negative pore fluid pressure generation is generally suppressed by the elasto-plasticity effects in the soil skeleton. It is evident that in an initially unstressed fluidsaturated porous medium, there can be negative pore fluid pressure induced for a period after the unloading process. Considering Terzaghi's principle of effective stresses, the negative pore fluid pressure can have a strengthening effect of the soil skeleton, leading to short-term apparent strengths that are higher than the innate strength of the medium when all pore fluid pressures have dissipated.

\subsection{Geophysics}

Geophysical exploration methods are tools for investigating the interior of the earth from the earth's surface. They are nondestructive and rely on recording and analysing physical fields extending or propagating in and around the earth. Examples are the gravity and magnetic fields and electromagnetic and seismic waves ("earthquake waves"). For prospecting both natural and artificially generated fields are used depending on the questions to be solved. In soil science the application of geophysical methods is
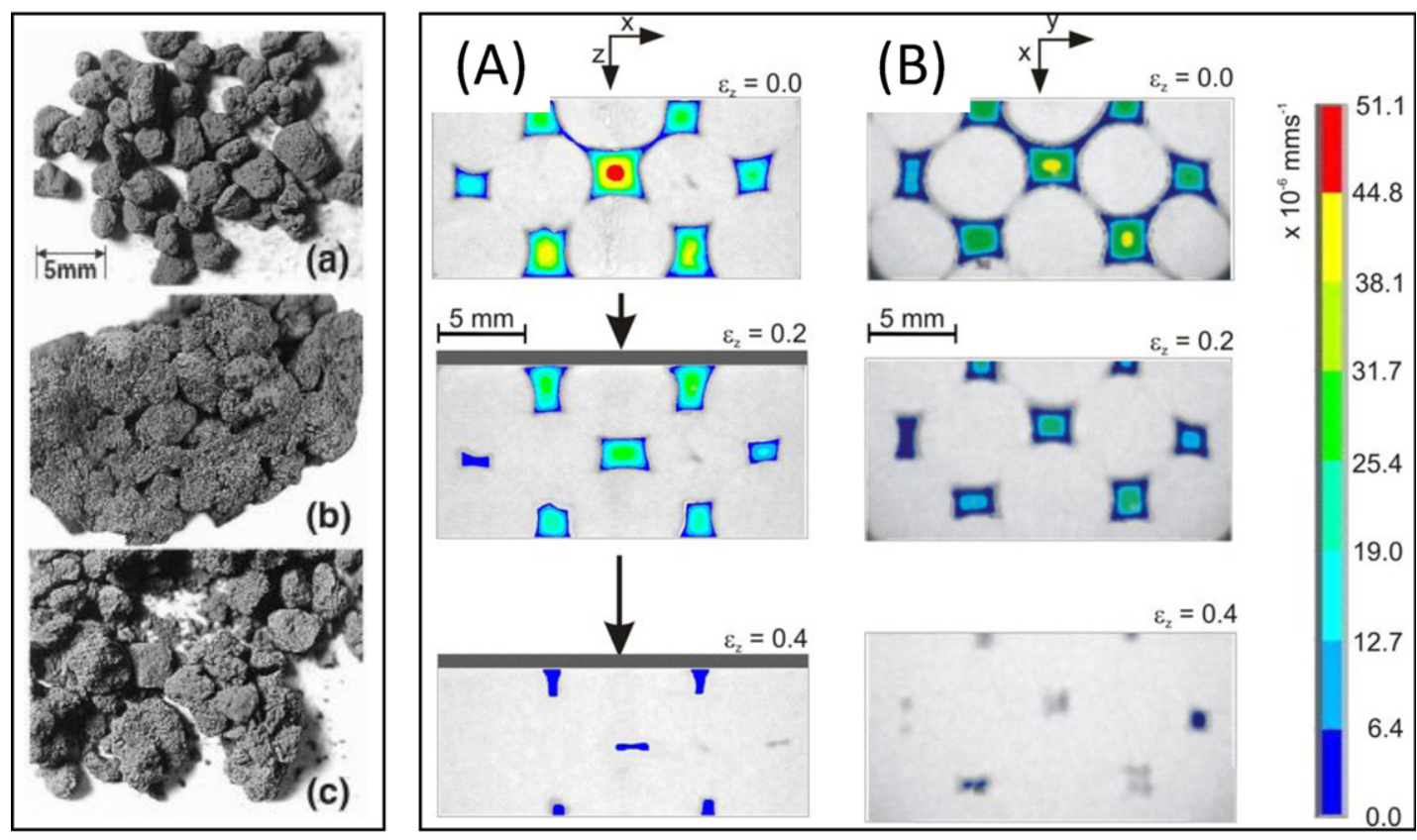

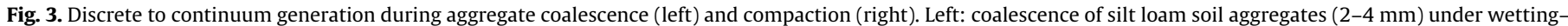

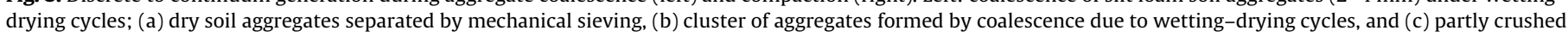

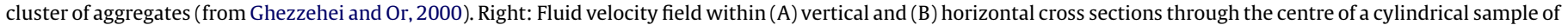
modelling clay spheres of $5 \mathrm{~mm}$ average diameter in octahedral packing as a function of vertical sample strain $\varepsilon_{z}$ of 0,20 , and $40 \%$.

From Eggers et al. (2007). 


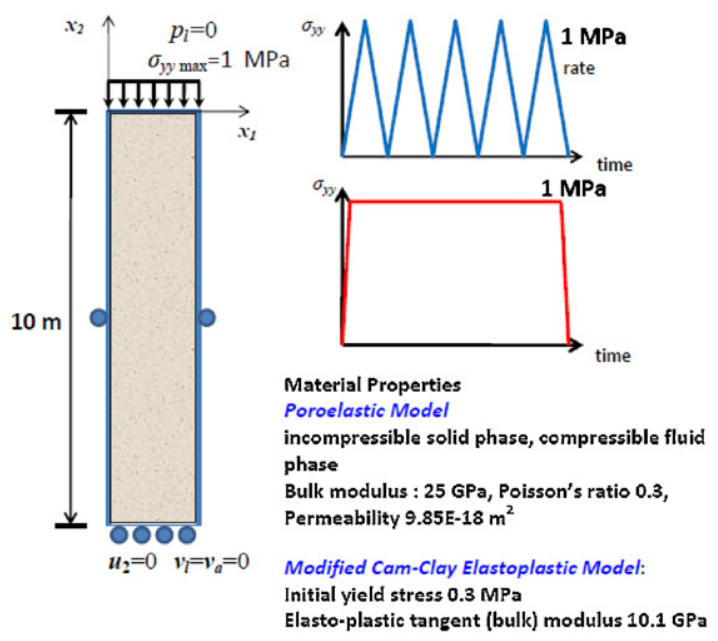

(b)

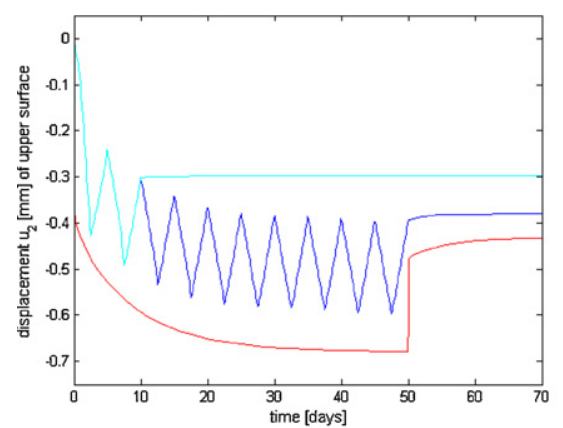

(c)

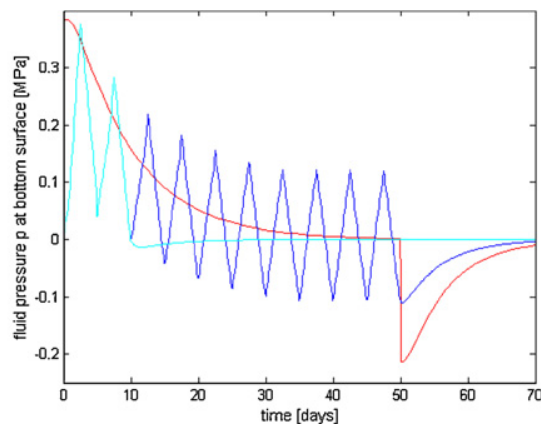

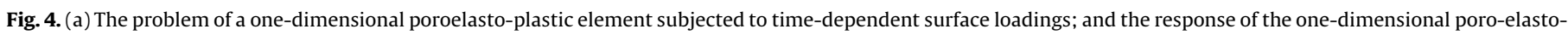
plastic element subjected to time-dependent surface loadings: (b) surface displacement, and (c) pore fluid pressures.

attractive because they are capable of continuously mapping larger areas in terms of physical subsurface parameters (e.g. Allred et al., 2008).

In order to decide whether or not a scientific problem for a soil can be approached by geophysical prospecting, the following needs to be investigated: (i) if the problem under consideration can be translated into temporal or spatial changes of the physical properties of the soil, and (ii) if these changes exceed the detection swell of the geophysical instruments. Examples are the clay content that maps into natural radioactivity (e.g. Fricke and Schön, 1999; van der Kloster et al., 2011), or the moisture content that influences the electrical conductivity and permittivity (e.g. Al Hagrey et al., 2004; Kirsch, 2010).

Soil compaction is connected with the following changes in the soil structure that are relevant for geophysical mapping: (i) a reduction of the porosity (or, conversely, an increase in density) leading to a decrease of the volume contents of soil air and pore water and an increase of the volume fraction of clay, (ii) a mechanical stiffening of the soil matrix, and (iii) a spatial rearrangement of soil grains and deformation of the soil fabric. These changes imply modifications of some soil physical properties, which can potentially be measured in the field with corresponding geophysical methods.

\subsubsection{Electrical conductivity}

The compaction-induced changes in the volume portions of the soil constituents have a strong influence on the electrical conductivity. Soils containing clay show a significant increase in electrical conductivity (and conversely, decrease in electrical resistivity) basically because the raising volume content of the highly conductive clay usually over-compensates the reduction of the also conductive pore fluid (e.g. Schön, 1996; Lück et al., 2009). Fabric changes that lead to a more intense connection between clay particles may also contribute to this effect. Besson et al. (2004) measured a difference in electrical resistivity of $10 \Omega \mathrm{m}$ between a compacted $\left(30 \Omega \mathrm{m}\right.$, bulk density $=1.59 \mathrm{Mg} \mathrm{m}^{-3}$ ) and a porous structure $\left(40 \Omega \mathrm{m}\right.$, bulk density $\left.=1.41 \mathrm{Mg} \mathrm{m}^{-3}\right)$ of a loamy soil. A decrease of electrical conductivity with compaction can be expected in pure sand only if the compaction leads to a reduction in the volumetric pore water content (which is not necessarily the case in the vadoze zone). The electrical conductivity can be measured in the field by DC-geoelectrical sounding, DC-geoelectrical tomography and electromagnetic induction measurements (EMI) (e.g. Corwin, 2008).

\subsubsection{Electrical permittivity}

The electrical permittivity or dielectric constant is influenced by compaction in a similar way as the electrical conductivity. It is basically sensitive to the general content of water in the soil because it expresses the capability of the soil to become electrically polarized. The permittivity can be determined via the propagation velocity and reflection amplitudes of electromagnetic waves in the radar frequency band by the use of ground radar equipment. However, ground penetrating radar (GPR) can hardly be applied in clay rich soil because its high electrical conductivity leads to a strong absorption of the radar waves in the ground (e.g. Kirsch, 2010). 

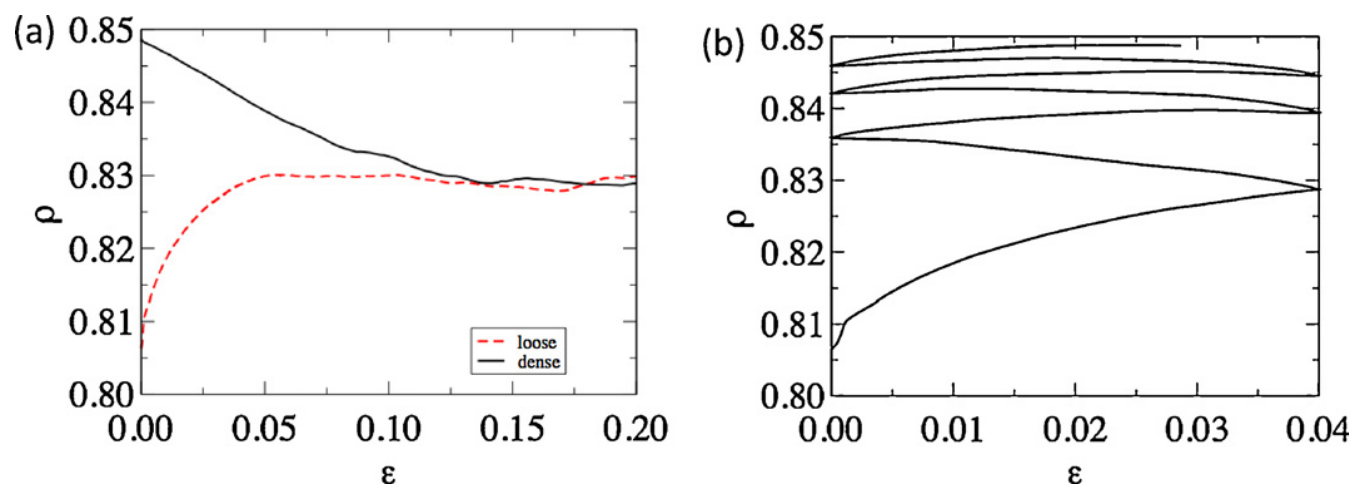

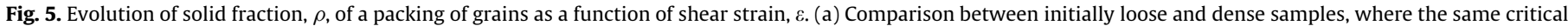
solid fraction is reached; and (b) effect of low amplitude cyclic deformation on the evolution of solid fraction.

From Radjai and Roux (2004).

\subsubsection{Seismic methods}

Seismic methods have seldom been applied to soil science research (Petersen et al., 2005) although these geophysical techniques offer an intuitive and direct approach to the characterization of the mechanical state and properties of soils. For the available soil science applications, seismic methods relied primarily on the analysis of seismic wave propagation velocities. The velocity of seismic waves depends on the soil elastic moduli, the bulk density, and on the degree of saturation of soil layers. The velocity of compressional waves ( $P$-waves), $v_{\mathrm{P}}$, is in the range of a few $\mathrm{km} \mathrm{s}^{-1}$ in rock ("earthquake waves"), and around 750 and $2000 \mathrm{~m} \mathrm{~s}^{-1}$ in consolidated dry and saturated sand, respectively. In unsaturated soil, $v_{\mathrm{P}}$ is typically lower than the speed of sound waves in $\operatorname{air}\left(335 \mathrm{~m} \mathrm{~s}^{-1}\right.$ ) (e.g. Baker et al., 1999).

One the primary effects of compaction is the stiffening of the soil and the alteration of the elastic moduli. The bulk density is also affected, but relative to changes in the soil elastic moduli, this effect tends to be minor. Soil compaction (i.e. an increase in bulk density) thus results in an increase in seismic wave propagation velocity. Uyanik (2010) reported values for $v_{\mathrm{P}}$ of 176 and $269 \mathrm{~m} \mathrm{~s}^{-1}$ for a clayey sand with a bulk density of 1.41 and $1.62 \mathrm{Mg} \mathrm{m}^{-3}$, respectively. In the field, depth profiles of seismic wave velocity can be measured with a variety of different methods used for the exploration of deep targets, such as aquifers or hydrocarbon reservoirs.

Geophysical mapping offer excellent means for gathering information on soil changes in space and time where the emphasis is on "change". The absolute values of geophysical soil properties usually do not translate directly into compositional and structural soil properties. The geophysical measurements need calibration and validation by classical soil analysis in order to account for the local field conditions, meaning that pedo-transfer functions have to be setup. Therefore, a combined application of methods from geophysics and soil science appears as a promising approach to investigate soil compaction.

\subsection{Physics of granular media}

Soil is composed of mineral and organic primary and compound particles of different shapes and sizes. The granular nature of the soil leads to a very large surface area. The inter-particle surface areas are the location of physical interactions of contact, friction, lubrication, capillary action or cementing cohesion. The macroscopic behaviour of soils emerges from the collective inter-particle interactions.

The classical approach (Section 2.2) is based on phenomenological relationships between macroscopic parameters, while a granular approach starts from the particle properties and interactions at the grain scale with the aim of deducing the homogenized behaviour of the material. A major advantage of the latter approach is the ability to account for the internal structure at various scales and to predict the rheological behaviour from the local physics under complex loading (Fig. 5). A number of new insights into the stress and strain inhomogeneities of soils have been obtained using the granular approach. For example, the complexity of stress transmission through force chains has been extensively studied and shown to be organized in two well-defined force networks: the weak network (forces below average) that does not contribute to shear stress, and the strong network that supports all the shear stress (Fig. 6) (Radjai et al., 1996, 1998). Such a structure shows both the weaknesses of a soil in response to external excitations and the real mechanisms of its stability. Another example, which is not accessible from continuum modelling, is the micromechanical origin of shear strength. It was recently shown that the internal angle of friction does not depend on the particle size distribution because the largest

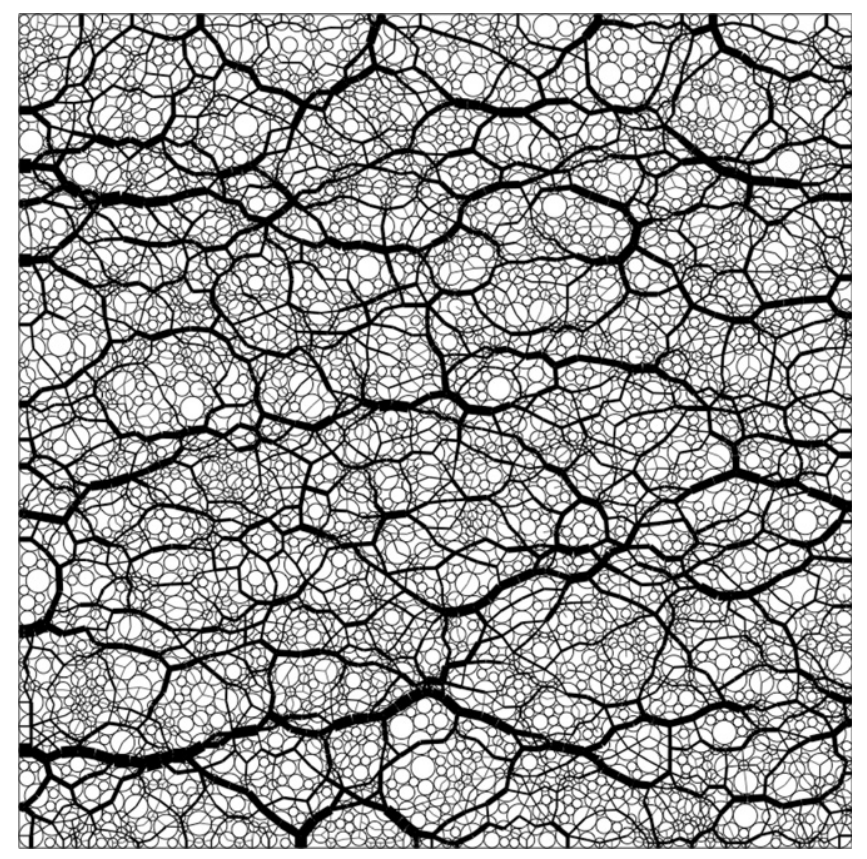

Fig. 6. Example of heterogeneous force transmission in a granular sample submitted to a confining pressure. The magnitude of the contact forces is proportional to the width of the inter-centre connecting segments. From Radjai et al. (1996). 
particles in the bulk material capture most of the strong force chains. The Coulomb cohesion is, however, found to be dependent on the particle size distribution (Voivret et al., 2009).

Experimental studies of model granular materials have been helpful in highlighting many phenomena inherent to their discrete structure. Besides the classical testing tools of soil mechanics, new experimental approaches have been developed for the measurement of individual particle displacements, contact forces, etc. For example, 2D photoelastic grains have been used to visualize the heterogeneity of local stresses in a granular material under compressive loading (Da Silva and Rajchenbach, 2000; Majmudar and Behringer, 2005). The methods based on imaging and Particle Image Velocimetry (PIV) have been used to study the elastic properties of granular assemblies at the grain scale (El Hadji Bouya et al., 2011). Experimental devices for studying stacks of polydisperse cylinders were performed in order to analyse the shear behaviour in line with the movements and the localization phenomena such as shear bands (Calvetti et al., 1997). For the study of saturated media, iso-index fluorescent liquid and grains have been used to track the motion of particles inside the volume with a laser sheet (Tsai et al., 2003). Today, new imaging techniques such as computed tomography ( $c f$. Section 4.1) open interesting perspectives for the granular approach and its applications to soils (Desrues et al., 2006).

In parallel to experimental methods, discrete element methods (DEM) have been developed over the last 30 years for the computation of large packings of particles with increasingly more complex interactions ( $c f$. Section 3.3). The availability of powerful computers has made it possible to investigate the mechanical behaviour of discrete models of soils. The mechanical behaviour of granular materials is influenced by various local properties such as particle size distribution (Voivret et al., 2007), frictional sliding and rolling (Estrada et al., 2008), particle shapes (Azéma et al., 2009), and cohesion (Delenne et al., 2004), and these aspects have become major fields of research.

Statistical homogenization concepts are also used in association with DEM to analyse the disordered local structures and to upscale the local behaviour to the macroscopic scale (Roux and Radjai, 2001). Simple relationships have been shown between the microscale parameters of cohesion, the strength properties at the macroscale (internal friction angle, dilatancy angle, and Coulomb cohesion) and the parameters describing the shape and polydispersity of the particles. The internal angle of friction is found to result from different contributions of geometrical, kinematic (due to dilation) and frictional origins (Taboada et al., 2006).

Granular physics is now a mature field with the potential for applicability to a variety of complex systems such as landslides and soil-root interactions (Taboada et al., 2005; Staron and Lajeunesse, 2009). This broad scope calls for a multidisciplinary approach using an innovative combination of concepts, experimental tools and numerical methods.

\section{Modelling approaches}

Models used to simulate the stress transmission and deformation in geomaterials can be divided into two groups: analytical models and numerical models. Analytical models assume elementary material laws (e.g. linear elasticity). Soil compaction models based on analytical approaches solve compaction in two steps: first, stress transfer, and second, deformation as a function of the calculated stress. Numerical models solve the deformation and stress simultaneously by satisfying the equilibrium equation. Numerical models include finite element and distinct (or discrete) element codes. These methods require computing power, and were first developed in the 1940's (finite element method) and 1970's (distinct element method).

\subsection{Analytical solutions for stress transmission}

Stress transmission is a topic that has been of scientific and engineering interest since the time of Archimedes and culminated in the concept that was proposed by Augustin Louis Cauchy (see e.g. Truesdell, 1961; Davis and Selvadurai, 1996). Cauchy simply assumed that the nature of the reactive forces generated during transmission of externally applied loads to the interior of a solid is no different from the tractions that are applied to the boundary of a stressed solid. Specific values for the tractions $\mathbf{T}$ acting on a plane located at the interior of the body are related to the stress state $\boldsymbol{\sigma}$ at a point through the relationship

$\mathbf{T}=\boldsymbol{\sigma} \mathbf{n}$

where $\mathbf{n}$ is the outward unit normal to the plane. This ability to define a measure for the state of stress within the body without consideration of the material properties of the geomaterial or its fabric was a major accomplishment in the development of mechanics of materials.

The spatial transmission of stresses within the geologic material requires knowledge of the manner in which the internal structure of the geomaterial responds to the externally applied loading through strains. There is no unique model of stress-strain behaviour that is universally applicable to geomaterials. The earliest application of analytical concepts dates back to the classical works of Rankine and Coulomb that were largely based on the stress distributions in geomaterials as they approached the state of failure (see Davis and Selvadurai, 2002).

The seminal analytical problem deals with the normal loading of the surface of an isotropic elastic halfspace by a concentrated force $P_{B}$, maintaining the unloaded region traction free (Fig. 7). In addition, the tractions far field from the point of application of the concentrated normal load should decay in such a fashion that the resultant of the far field tractions should balance the normal force applied at the boundary. The solution to this classical problem is due to Boussinesq (1885). The static boundary value problem requires the solution of the governing Eqs. (12-14) (with zero body forces and dynamic terms):

$\boldsymbol{\sigma}=\lambda e \mathbf{I}+2 \mu \varepsilon$

$\boldsymbol{\varepsilon}=\frac{1}{2}\left[\nabla \mathbf{u}+(\nabla \mathbf{u})^{T}\right] ; e=\operatorname{tr} \boldsymbol{\varepsilon}$

$\nabla \boldsymbol{\sigma}+\mathbf{f}=\rho \frac{\partial^{2} \mathbf{u}}{\partial t^{2}}$

where $\nabla$ denotes the gradient operator, $\operatorname{tr}$ denotes the trace, $\mathbf{f}$ is a body force vector and $\rho$ is the mass density. Since the concentrated

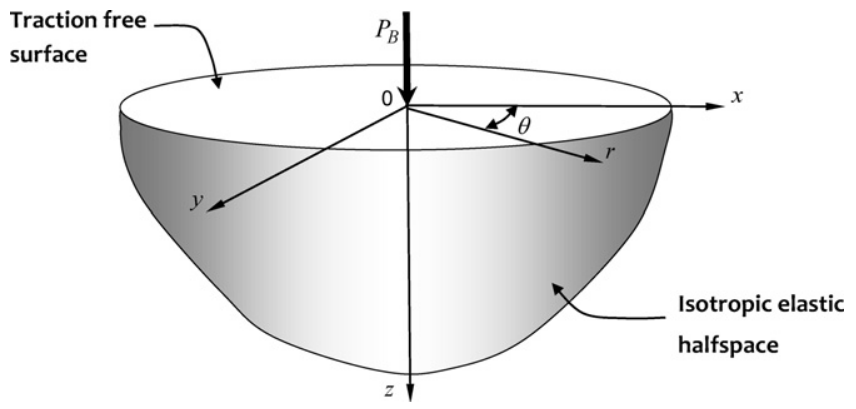

Fig. 7. Boussinesq's problem for an isotropic elastic halfspace. 
force acts normal to the surface of the halfspace, there exists a state of symmetry about the $z$-axis, which allows the problem to be formulated as an axisymmetric problem related to the cylindrical polar coordinate system $(r, \theta, z)$, and the displacement and stress fields can be expressed as follows (see e.g. Timoshenko and Goodier, 1970; Davis and Selvadurai, 1996):

$$
\begin{aligned}
& u_{r}(r, z)=\frac{P_{B}}{4 \pi \mu R}\left(\frac{r z}{R^{2}}-\frac{(1-2 v) r}{R+z}\right) \\
& u_{\theta}(r, z)=0 \\
& u_{z}(r, z)=\frac{P_{B}}{4 \pi \mu R}\left(2(1-v)+\frac{z^{2}}{R^{2}}\right) \\
& \text { and }
\end{aligned}
$$

$$
\begin{aligned}
& \sigma_{r r}(r, z)=\frac{P_{B}}{2 \pi}\left(\frac{3 r^{2} z}{R^{5}}-\frac{(1-2 v)}{R(R+z)}\right) \\
& \sigma_{\theta \theta}(r, z)=\frac{P_{B}(1-2 v)}{2 \pi}\left(\frac{1}{R(R+z)}-\frac{z}{R^{3}}\right) \\
& \sigma_{z z}(r, z)=\frac{P_{B}}{2 \pi}\left(\frac{3 z^{3}}{R^{5}}\right) \\
& \sigma_{r z}(r, z)=\frac{P_{B}}{2 \pi}\left(\frac{3 r z^{2}}{R^{5}}\right) \\
& \sigma_{r \theta}=\sigma_{\theta z}=0
\end{aligned}
$$

where $R=\left(x^{2}+y^{2}+z^{2}\right)^{1 / 2}$. For relatively simple loadings (e.g. circular load with uniform stress intensity), expressions can be developed to calculate the transmission of stress within the halfspace region due to the surface loading (see e.g. Davis and Selvadurai, 1996).

Empirical knowledge of stress propagation is available from comprehensive studies reporting stress measurements in undisturbed soil profiles, including investigations of the effects of contact area and stress distribution at the tyre-soil interface (see e.g. Keller and Lamandé, 2010) and soil conditions (e.g. Horn et al., 2003; Trautner and Arvidsson, 2003; Lamandé and Schjønning, 2011) on stress transfer. The rate of decay of the stress predicted by the classical theory of elasticity is found to be at variance with experimental observations, in particular the vertical stress distributions within the geomaterial regions. The work of Fröhlich (1934) is an empirical development that adjusts the form of the vertical stress $\sigma_{\mathrm{zz}}(r, z)$ derived from Boussinesq's solution by introducing a "concentration factor", $n$, which allows the alteration of the decay pattern to suit an experimentally observed pattern. Fröhlich's model is widely used in agricultural soil mechanics (e.g. Keller and Lamandé, 2010). The mathematical basis for the introduction of this concept is lacking, in the sense that there appears to be no formal linear solution of the equations governing the classical theory of elasticity (i.e. Eqs. (12-14)), that will yield a solution to Boussinesq's problem for the action of a concentrated force $P_{B}$ normal to the surface of an elastic halfspace in the form

$\sigma_{z z}(r, z)=\frac{n P_{B} z^{n}}{2 \pi R^{n+2}} ; R=\sqrt{r^{2}+z^{2}}$

A critical mathematical examination of Fröhlich's solution to Boussinesq's problem is provided by Selvadurai (2012). Analytical soil compaction models have the advantage in that they are simple to use, require few input parameters and are robust.

\subsubsection{Influence of geomaterial inhomogeneity on stress transmission}

Geomaterials are inherently inhomogeneous at any scale. The general approach for dealing with geomaterial heterogeneity is to consider effective material parameters applicable to units consisting of variable mechanical properties.

The inhomogeneity in the deformability characteristics that is of particular importance to soil tillage mechanics and stress transmission is the layered soil profile that can develop through pedo- and/or geogenetic processes or due to periodic compaction and tillage of the soil. This type of soil inhomogeneity is characterized by mechanical properties that are assigned to distinct strata. The layered elastic system approach to estimate stress transmission has been extensively studied in connection with transportation infrastructure analysis (Poulos and Davis, 1975). Analytical solutions exist for the settlement of layered systems such as the problem of an elastic layer that rests on a rigid base (see Davis and Selvadurai, 1996); however, these are of limited interest to soil science.

\subsection{The finite element method}

The finite element method (FEM) is a numerical approach for solving differential equations describing any kind of physical phenomena in a continuous medium for which analytical solutions do not exist, are available only for very simple cases, or are too complex. The original differential equations describing a specific problem are replaced by a finite set of equations which can be solved numerically. This requires subdividing the continuum into a number of elements that are connected to each other via nodes (spatial discretization). The FEM allows the treatment of complex geometries of heterogeneous problems. FEM was employed for the first time in the 1950s in the construction of airplanes and the design of bridges (Bear and Verruijt, 1987; Zienkiewicz and Taylor, 2000). The concept of FEM was later generalized and, along with increasing computer power, became a standard tool in almost all areas of engineering, physics and environmental sciences. The FEM has also been successfully applied to a wide range of soil related problems with geotechnical, environmental or agricultural aspects. Examples include the analysis of water flow, chemical and heat transport in soils and aquifers (e.g. Bear and Verruijt, 1987; Radcliff and Simunek, 2010), soil-implement interactions (e.g. Kushwaha et al., 1993; Abu-Hamdeh and Reeder, 2003), slope stability and foundations (Griffiths and Lane, 1999; Zdravkovic and Carter, 2008; Danno and Kimura, 2009), and soil compaction (see review by Défossez and Richard, 2002). FEM has also been applied to small scale deformation processes, for instance, those associated with lateral root expansion (Richards and Greacen, 1986) and its effect on hydraulic conductivity (Aravena et al., 2011). Today, a variety of commercial FE programs are available (multiphysics programs such as ABAQUS (Abaqus FEA, D S Simulia, Dassault Systems) and COMSOL (COMSOL Multiphysics, COMSOL AB) or codes designed for geotechnical purposes such as PLAXIS (Brinkgreve, 2002)), as well as non-commercial FEM developed for soil compaction research (e.g. Richards, 1992; Gysi et al., 2000).

\subsubsection{Essential ingredients of the FEM}

A comprehensive treatment of the FEM including its application for non-linear problems for plastic and viscoplastic behaviour is provided in Zienkiewicz and Taylor (1994a). Here, only the basic steps and notations of the FEM will be outlined.

The first step in FE analysis is the discretization of the continuum into a finite number of elements (in 2D: triangles or quadrilaterals), which are connected via nodes building a FE mesh as a substitute for the continuum. Each element consists of a number of nodes. Nodes are assigned nodal parameter values (e.g. pressure, velocity, displacement, etc.). In deformation analysis most FE programs use a displacement formulation where the strain within an element is defined in terms of nodal displacements. Initial strains plus strains associated with the nodal displacements define the state of stress within an element and on its boundaries based on the constitutive properties of the material (Zienkiewicz and Taylor, 1994b). The displacements $u$ at any point within an element $(e)$ can be approximated by a column vector $\hat{\mathbf{u}}$, which is 
obtained from prescribed functions of position $N_{i}$ and nodal displacements $u_{i}$ for a particular element:

$\hat{\mathbf{u}}=\left[N_{1}, N_{2}, N_{3}\right]\left\{\begin{array}{l}u_{1} \\ u_{2} \\ u_{3}\end{array}\right\}^{e}=\mathbf{N u}^{e}$

where $\mathbf{N}$ is the matrix of interpolation functions (also referred to as shape function) and $\mathbf{u}^{e}$ is the displacement vector of an element. With the nodal displacements determining the distortion of the element the spatial derivative of the displacement functions yields the strains at any point:

$\boldsymbol{\varepsilon}=\mathbf{B u}^{e}$

where $\mathbf{B}$ is the element strain matrix and $\boldsymbol{\varepsilon}$ the strain vector of any point in an element. Assuming linear elastic material behaviour, the stresses are obtained from the strains and the corresponding elastic material properties:

$\sigma=\mathbf{D}\left(\varepsilon-\varepsilon_{0}\right)+\sigma_{0}$

where $\mathbf{D}$ is the elastic stress (material constitutive) matrix, $\varepsilon_{0}$ is the initial strain and $\sigma_{0}$ is the initial residual stress. Using the principle of virtual work, a nodal force-displacement relationship can finally be established (Zienkiewicz and Taylor, 1994b):

$\mathbf{q}^{e}=\mathbf{K}^{e} \mathbf{u}^{e}+\mathbf{f}^{e}$

where $\mathbf{q}^{e}$ is the nodal force vector, $\mathbf{K}^{e}$ is the elastic stiffness matrix, and $\mathbf{f}^{e}$ represents forces due to body forces, initial strain, and initial stress, respectively.

For a two-dimensional plane stress elastic problem the total strain $\varepsilon$ in Eq. (19) at any point within an element can be defined by three strain components $\boldsymbol{\varepsilon}_{x}=\partial u / \partial x, \boldsymbol{\varepsilon}_{y}=\partial v / \partial y$, and $\boldsymbol{\gamma}=(\partial u /$ $\partial y+\partial v / \partial x)$ with $u, v$ being the displacement components parallel to the $x$ - and $y$-axis, respectively. Assuming an isotropic material and considering the constitutive stress-strain relation, the corresponding stress components are given by:

$\sigma_{x}=\frac{E}{1-v^{2}}\left(\varepsilon_{x}+v \varepsilon_{y}\right)$

$\sigma_{y}=\frac{E}{1-v^{2}}\left(\varepsilon_{y}+v \varepsilon_{x}\right)$

$\tau=\frac{E}{2(1+v)} \gamma=G \gamma$

where $E$ is the elastic modulus, $v$ is the Poisson's ratio and $G$ the shear modulus. Note that the elastic moduli $E, G$ and $K$ (bulk modulus) are related according to:

$G=\frac{E}{2(1+v)}$

$K=\frac{E}{3(1-2 \nu)}$

The material parameters (i.e. $K, G$ and $E$ ) used in the material constitutive matrix $\mathbf{D}$ and the elastic stiffness matrix $\mathbf{K}$, are often highly non-linear and hysteretic for soils, i.e. mechanical material properties are stress-state dependent. Therefore, it is not possible to provide general values for the above properties, but for unsaturated arable soil, $E$ is typically of the order of $10 \mathrm{MPa}$, and a typical value for the Poisson's ratio of soil is $v=0.3$. Using the modified "hyperbolic" formulae of Nelson (1970), stress-dependent moduli have been formulated by Richards (1992):

$K=k_{1} \sigma_{m}^{n}+k_{2} h^{m}+k_{0}$
$G=\left(g_{1} \sigma_{m}^{p}+g_{2} h^{r}\right)\left[1-\left(\frac{\tau}{\tau_{f}}\right)^{q}\right]+g_{0}$

where $\sigma_{m}$ is the previous maximum of the mean normal stress, $h$ is the soil water suction, $\tau$ is the shear stress and $\tau_{f}$ the yield stress (e.g. Mohr-Coulomb failure criterion). The other parameters $k_{0} \ldots$ $k_{2}, g_{0} \ldots g_{2}, n, m, p, r$, and $q$ are empirical material constants, which can be determined from mechanical soil test data (Peth et al., 2006).

\subsubsection{Potential and limitations of modelling soil compaction with FEM}

The FEM has been successfully applied to a range of soil and environmental problems. It does, however, require a greater effort to thoroughly characterize the mechanical material properties based on soil testing in order to derive parameters for the nonlinear stress-strain relationship encountered in soils. Traditionally, standard soil tests with static loading or constant displacement rates, such as direct shear tests, confined consolidation tests (oedometer) or triaxial tests, are employed to obtain shear $(G)$ and bulk moduli $(K)$ for FEM simulations. However, the stress paths followed in such "static" soil tests do not realistically represent the short-term dynamic loading situation in the field (Keller and Lamandé, 2010; Peth et al., 2010a).

Among the primary limitations of FEM are numerical challenges to consider large strain rates, and limited representation of opening and closure of pores and cracks.

During dynamic soil loading pore water pressure evolution has a significant effect on the deformation process. A FE-model for simulating the interaction between hydraulic and mechanical processes in soils has been presented by Gräsle et al. (1995), based on previous work of Richards (1992). Despite an advanced understanding of the theoretical principles governing deformation behaviour of unsaturated soils (Fredlund and Rahardjo, 1993) and the availability of FEM for solving complex coupled processes, the major obstacle in using such models seems to be the lack of an adequate quantitative description of the relevant soil properties by means of suitable in situ and laboratory tests.

The FEM is based on a continuum approach, but for structured soils in particular, this assumption can be problematic, for example to simulate the effect of deformation on transport functions (see also Section 2.1.3). In structured soils numerous macro-scale discontinuities are present (cracks, large biopores, etc.), which are of paramount importance for gas and water movement. This has lead to a two-domain or dual-permeability approach in modelling water and solute transport by assuming multiple continua (e.g. Gerke, 2006). However, the representation of the effective local (structural) geometry of the conducting pores, and the effects of soil structure dynamics on the pore space geometry and hence transport processes remains a challenge. Recent advances involve multiscale FE approaches (e.g. He and Ren, 2009) and non-invasive characterization of the pore network dynamics (cf. Section 4.1).

\subsection{The discrete element method}

The discrete element approach comprises a large class of numerical methods for the simulation of a collection of particles interacting through frictional contacts and collisions (Radjai and Dubois, 2011). Different variants of these discrete element methods (DEM) have been developed for the simulation of granular packings and slow deformations (Radjai and Roux, 2002), dense granular flows (da Cruz et al., 2005), and granular gases (McNamara and Young, 1992). Two major variants of DEM are Molecular Dynamics (MD), also simply called DEM following Cundall (Cundall and Strack, 1979), and Contact Dynamics (CD) initiated by Moreau and Jean (Moreau, 1994; Jean, 1999). 
The discrete element approach is based on the integration of the equations of motion simultaneously for all particles, described as rigid elements, by considering the contact forces as well as the external forces acting on the particles (Radjai and Dubois, 2011). Given the boundary conditions, the mechanical response of a collection of particles to external loading leads to relative particle motions constrained by steric exclusions in a dense state and/or by inelastic collisions in a loose or dilute state (Moreau, 1994).

The main difference between MD and CD is in the numerical modelling of frictional contact. In MD the contact force is described as a function of a local strain defined from particle positions. These forces are regular functions (twice differentiable) of the relative positions $\delta$ of particles and their time derivatives. Hence, the time discretization must be adapted to correctly describe force laws across the contact. In contrast to the MD method, where an explicit scheme is used to solve the equations of motion by introducing stiff repulsive potentials and viscous damping between particles, the $\mathrm{CD}$ method is based on an implicit scheme involving an iterative Gauss-Seidel algorithm yielding, simultaneously, the contact forces and particle displacements at the end of each time step. This iterative process is defined so that it satisfies the kinematic constraints related to mutual exclusions of particles and the Coulomb friction law. For this reason, the CD method is unconditionally stable and does not require elastic repulsive potential between particles. This allows for larger time steps than in $\mathrm{MD}$, in particular in the limit of highly stiff particles or very low confining stresses.

A typical DEM computation loop proceeds in three steps:

(i) Determination of the list of nearest neighbours and contacts between particles from their current positions;

(ii) Integration of the equations of motion of all particles over a single time step to calculate the contact forces and velocities; and

(iii) Updating the particle positions.

Three levels of complexity may be discerned in DEM algorithms. The first (basic) level is based on a minimalistic description of the material with spherical grains interacting via frictional contacts. This elementary algorithm is already rich enough to reproduce emergent behaviours of granular materials under complex loading. The second level involves an enriched description of particle shapes and size distributions as well as their interactions via various adhesion forces. The third level deals with advanced processes and interactions such as particle fragmentation, hydrodynamic interactions in the presence of a fluid or particles embedded in a solid matrix. Coupled continuum-discrete algorithms are often required to treat such problems. For example, the methods relying on subparticle meshing of the particles, such as the Lattice Element Method (LEM), may be used to introduce particle fragmentation (Topin et al., 2007). Another example concerns fluid-grain interactions in which the continuum mechanics of fluids must be combined with discrete mechanics. Different approaches have been proposed to compute the evolution of the fluid phase between particles, such as the Lattice Boltzmann method (Mansouri et al., 2009), or Direct Numerical Simulation (Wachs, 2009).

During the last 30 years, many examples of experimental validation have established DEM as an efficient and effective methodology to address physical and engineering issues dealing with a wide variety of materials including soils, powder processes, gravitational flows and instabilities, etc. Many studies reported in the literature concern homogenous boundary conditions with the aim of investigating the grain-scale origins of effective properties such as shear strength, dilatancy, creep, etc., and the microstructure. Three-dimensional simulations of large systems of particles with realistic shapes and size distributions are still computationally intensive and require special optimizations to save simulation time; the scope of large-scale simulations for application to complex systems and processes is broad and promising.

Challenges in the application of DEM in soil compaction research include (see also Shmulevich, 2010): (i) physical interpretation and determination of the constitutive micromechanical model parameters that represent the mechanical properties of soil, (ii) modelling of the real (span of) particle size and shape, and (iii) modelling of the process of breakage and formation of compound particles (fragments, aggregates).

\section{Non-destructive measurement techniques for soil structure and deformation}

Non-destructive (non-invasive) measuring techniques such as computed tomography offer an excellent means for characterization and quantification of soil structure from the aggregate to the soil core scale (e.g. Tuller et al., 2010). Geophysical methods are also non-invasive, and allow for in situ measurements of larger scale structures at the field scale. The propagation of seismic waves, for example, is a function of the structure, the mechanical properties and the moisture status (distribution of solids, water and air) of the geomaterial. Knowledge of structural properties across scales will advance the characterization of heterogeneities in continuum-based approaches, and hence improve the predictability of soil compaction processes in complex porous media such as soils. Furthermore, the non-invasive techniques provide an insight into the dynamics of soil structure.

\subsection{Computed tomography}

\subsubsection{Background}

Computed tomography $(\mathrm{CT})$ has been a tool in soil research since the pioneering work of Petrovic et al. (1982). Analysing soil and glass bead samples with a medical scanner, they determined bulk density variation at a spatial resolution of $1.25 \times 1.25 \times 2 \mathrm{~mm}^{3}$, and highlighted the method as "potentially promising tool for research in the areas of compaction, soil management, and cultivation". One of the first papers studying soil compaction using CT was published by Vaz et al. (1989), who detected thin compacted layers at the ploughing depth. Other work where soil compaction/deformation was investigated with $\mathrm{CT}$ (including $\gamma$-ray and X-ray based systems) treated effects of compaction on earthworm burrowing (Langmaack et al., 1999; Jégou et al., 2002), different tillage management systems (Wiermann et al., 2000; Gantzer and Anderson, 2002; Pedrotti et al., 2005; Mikita et al., 2009; Kim et al., 2010), trafficked sewage-sludgetreated soils (Pires et al., 2003), puddling induced compaction in paddy-soils (Sander et al., 2008), and soil structure regeneration after compaction by wetting and drying (Werner and Werner, 2001; Pires et al., 2005, 2007).

Over the last 10 years, high resolution tube and synchrotronbased microtomography systems have brought significant quality improvements in terms of acquisition time, resolution, and signal to noise ratios, allowing studies of local deformation processes at the $\mathrm{mm}$ to $\mu \mathrm{m}$-scale. Examples are the investigation of compression around roots (Aravena et al., 2011) and earthworm burrows (Rogasik et al., 2003; Schrader et al., 2007), and the effect of hydraulic and mechanical stresses on the dynamics of soil pore system (Schäffer et al., 2008b; Peth et al., 2010b). CT-images can be rendered into a 3D volume containing the spatial configuration of voids and solids, allowing quantitative morphological and topological characterization of the pore space (Vogel, 1997; Horgan, 1998; Delerue et al., 1999; Peth et al., 2008).

$\mathrm{X}$-ray computed tomography setups can be classified into three different types: (1) medical scanners (XCT or short CT), (2) 
industrial tube based microtomography systems (XCMT or $\mu \mathrm{CT}$ ) and (3) synchrotron-based microtomography systems (SR- $\mu \mathrm{CT}$ ). The physical principle underlying all systems is that an incident $\mathrm{X}$ ray beam with a given energy is absorbed by the material components of the radiated object (see e.g. Peth, 2011).

\subsubsection{Potential and limitations of $C T$ and $\mu C T$ in soil compaction research}

The potential of X-ray CT and $\mu \mathrm{CT}$ in soil compaction research is that it is non-invasive, permitting the mapping of the spatial arrangement of soil constituents and pores without disturbing the sample structure. This is an important improvement over traditional methods, where structural properties of soils (e.g. pore size distribution) are measured indirectly from water retention functions or directly by thin section microscopy, which risk undesired modification of structural features during measurement (by hydraulic stresses) or sample preparation (dehydration using acetone and impregnation with resin).

Hydraulic stresses may cause significant soil deformation by inducing swelling and shrinkage through capillary forces. The nonrigidity of the pore space architecture results in unreliable estimates of e.g. water retention functions. This problem could be overcome by repeatedly scanning the same sample under different hydraulic stress states, and relating the morphology/ topology of a pore network to its transport functions at various moisture conditions in order to derive hydraulic properties/ functions as a function of soil matric potential. Similar approaches could be used for quantifying the impact of mechanical stresses on soil functions, and ultimately also for the coupling of mechanical and hydraulic stress to account for the influence of water on the mechanical behaviour of soil.

Systematic non-invasive studies of changes in pore space due to soil deformation by mechanical and hydraulic stresses could inspire/facilitate the development and validation of new approaches in soil compaction modelling (see also Section 5). For example, CT or $\mu \mathrm{CT}$ image analysis techniques were used by Schäffer et al. (2008a,b) to study the stability and deformation of artificially generated macropores under uniaxial compression, by Kremer et al. (2002) to investigate the deformation of macropores under varying load and soil moisture conditions, and by Berli et al. (2008) to develop and test an analytical model describing the evolution of aggregate contact sizes with compression as a key determinant of unsaturated water flow. Modern techniques such as digital image correlation have successfully been used in combination with $\mu \mathrm{CT}$ analysis to localize soil strain (Peth et al., 2010b) demonstrating the highly heterogeneous and complex deformation field in structured soils and the influence of water on the deformation process (Fig. 8).

Despite the great potential of $(\mu) \mathrm{CT}$ as a non-invasive tool for investigating soil deformation processes, resolution is limited and does not cover the complete range of pore sizes encountered in soils. Modern CT-scanners are able to provide a voxel resolution of slightly better than 1:1000 of the sample diameter. Hence, the smaller the structure of interest the smaller the sample has to be, which conflicts with the scale-dependent spatial heterogeneity of soils. Covering the hierarchy of pore spaces from large inter-aggregate cracks and continuous biopores to small intra-aggregate micropores is not easily done and requires the extraction and analysis of subsamples. Another challenge is the extrapolation of pore scale effects of soil deformation and related changes in soil functions measured on soil cores to the soil management level (pedon and field scale).

\subsection{Scanning electron microscopy}

The first commercial scanning electron microscope (SEM) was constructed by Cambridge Scientific Instruments in 1965, based on the concept of Vladimir Zworykin (Zworykin and Ramberg, 1941; Zworykin et al., 1942). Today there are several types of instruments that work according to this principle. A detailed description of SEM, microanalysis and their application is given in Goldstein (2003).

SEM is a method commonly used in material science, medical research, and geosciences including applied clay science and soil micromorphology. SEMs deliver important data about particle properties, i.e. structure, shape and surface properties, and allow a visual identification of physicochemical compounds such as (clay) minerals, (hydr)oxides, organic matter, and fungal hyphae (Markgraf and Horn, 2006; Markgraf et al., 2012).

In soil science, SEM analysis is performed on (oven-dried) samples such as micro aggregates $(<250 \mu \mathrm{m})$ or isolated features (e.g. oxides or clay minerals). SEM analyses require good conductivity, which is achieved by gold-palladium coating (sputtering) of the sample under high vacuum conditions. SEM micrographs are obtained at $15 \mathrm{KeV}$ at a working distance of $15 \mathrm{~mm}$. Monochrome photographs are taken with a reflex camera, which is integrated in a SEM work station as an external unit. The latest generation of SEM chambers support fast and easy 3D stereo imaging via PC-controlled beam deflection with optional 3D surface modelling and analysis. Furthermore, they provide a choice of different chambers and stages with a high resolution analytical geometry for Energy Dispersive X-ray (EDX) analysis. If no high vacuum conditions are applicable, environmental scanning electron microscopy (ESEM) is a suitable method. a)

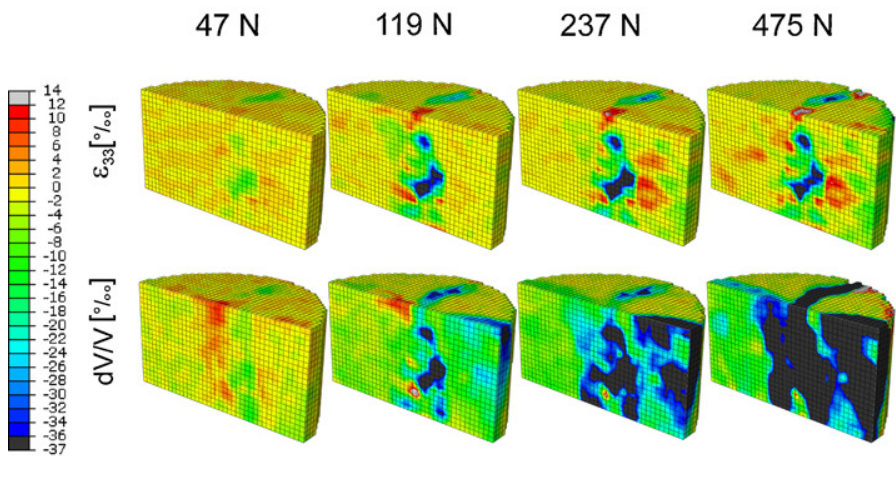

b)
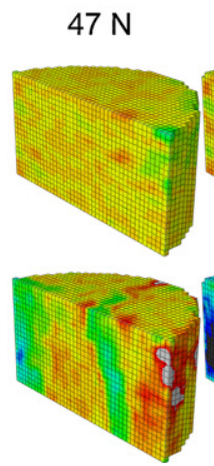

$119 \mathrm{~N}$
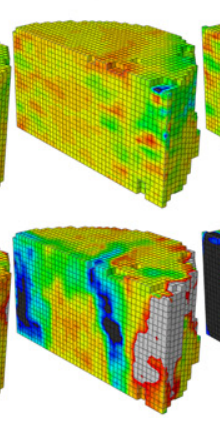

$237 \mathrm{~N}$
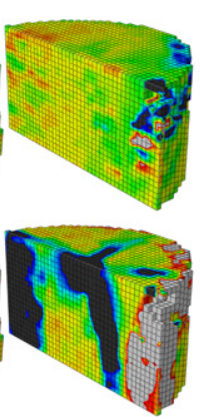

$475 \mathrm{~N}$

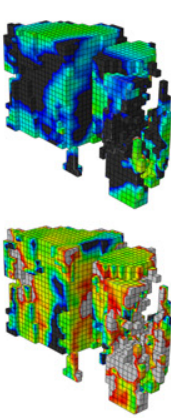

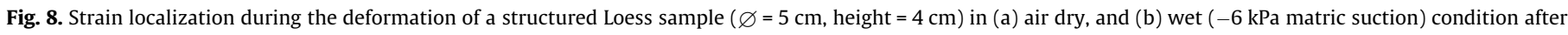

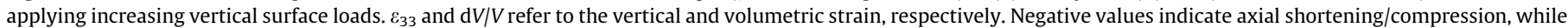
positive values indicate axial extension/loosening. Further details on the experimental setup and data analysis can be found in Peth et al. (2010b).

Modified after Peth et al. (2012). 
SEM is convenient for use with a combination with other mineralogical methods, e.g. X-ray diffractometry (XRD), atomic force spectroscopy (AFS), micromechanical techniques (rheometry), and non-invasive 3D visualizing techniques such as $\mu \mathrm{CT}$ (previous section), and such combinations are powerful tools for interpreting micro-scale attributes.

\subsection{Seismic methods}

The application of seismic waves is the most direct way to approach soil compaction from a "remote sensing" point of view. Unlike invasive methods (e.g. cone penetration tests) that reveal discrete information, seismic wave analysis yields integral values of mechanical properties representing volumes of metre scale in diameter and decimetre scale in vertical resolution.

There are basically four types of seismic waves that can be applied to analyse soils in situ (see e.g. Sheriff and Geldart, 1995; Rabbel, 2010): two body waves that can travel through the earth in any direction, and two surface waves that travel along the earth's surface. The latter have a very limited penetration depth, which is dependent on the wavelength. The body waves are compression waves ( $P$-waves) and shear waves ( $S$-waves). The propagation velocities of $P$ - and $S$-waves are:

$v_{p}=\left(\frac{K+4 G / 3}{\rho}\right)^{1 / 2}$

and

$v_{s}=\left(\frac{G}{\rho}\right)^{1 / 2}$

where $K$ is the bulk modulus, $G$ is the shear modulus and $\rho$ is the density of soil. The velocities depend mainly on $K$ and $G$, because $\rho$ is less variable than $K$ and $G$ in soils. The two surface wave types are Rayleigh and Love waves. Rayleigh waves show an elliptical particle movement in the vertical plane, whereas Love waves show a shear movement in the horizontal plane. Unfortunately, no closed-form expressions exist for the propagation velocities $v_{\mathrm{R}}$ and $v_{\mathrm{L}}$ of these waves. The penetration depth and $v_{\mathrm{R}}$ and $v_{\mathrm{L}}$ depend on the signal frequency, strongly on $K$ and only weakly on $\rho$. In addition, $v_{\mathrm{R}}$ depends weakly on $K$.

A fundamental problem exists in the different time scales and stress magnitudes applied in seismic and geomechanical measurements. No general framework exists that describes the soil stressstrain relationship for different time and stress scales including all non-linear, visco-elastic and plastic aspects. However, empirical data from long term and seismic measurements in engineering geology and reservoir research have shown that correlations exist between static and dynamic elastic constants (Schön, 1996; Hagin and Zoback, 2004). In particular, it has been shown that the shear wave velocity (or the shear modulus) correlates with the cone penetration resistance and shear strength of sediments (Suyama et al., 1983; Ayres and Theilen, 1999). We see this as an indication that investigating soils by comparing seismic and soil mechanic properties would have good chances of success, as further discussed in Section 5. For near surface seismic investigations it is common practice to artificially generate seismic waves by hitting the ground at some source points with a hammer or by shaking the ground in a cyclic way with a so-called vibroseis source (e.g. Rabbel, 2010). The radiated seismic signals are recorded along a line of sensors ("geophones") that are attached firmly to the ground with steel spikes. For the investigation of soils these geophone lines need to be some meters long with sensor spacing in the order of $0.1-0.2 \mathrm{~m}$. This measurement configuration is simply a downscaled version of that used for deeper targets, which is adequate for test measurements, but not suitable for the investigation of large agricultural areas. For this purpose, mobile equipment would have to be developed, which is an engineering issue. A comparison of interpretation techniques has shown that a sufficient depth resolution of seismic soil structure is difficult to achieve with body waves because a sensor spacing below $0.1 \mathrm{~m}$ is required near the source points, which is difficult to realise (e.g. Rabbel, 2010). This problem is not acute in surface wave analysis, giving them a clear preference for seismic measurements in soil science.

\section{Synthesis: potentials and challenges}

The objective of this section is to present and discuss approaches that could potentially lead to improved understanding of soil deformation processes. In the previous sections, we have identified two key issues that distinguish agricultural soil mechanics from geomechanics and that have a huge impact on soil mechanical behaviour: soil structure and loading rate. These issues deserve further attention in agricultural soil compaction research and are therefore discussed in this chapter. Modelling mechanical soil behaviour needs to account for anisotropy and scale- and time-dependency of soil physical properties. Here, we attempt to approach soil mechanical behaviour from different angles, and believe that the combination of (different) modelling (approaches) and non-invasive measurements as presented in the previous chapters has potential in advancing the understanding of soil deformation processes.

\subsection{Scale-dependent soil structural organization and how it influences soil strength, stress transmission and soil deformation}

Arable soil can possess various physical configurations as illustrated in Fig. 3. Soil structure is dynamic (and hence the soil physical and mechanical properties are dynamic too) and may evolve from a material that resembles a granular material (e.g. soil structure that results from tillage) to a quasi-continuum due to overburden, external stresses and capillary forces (Fig. 3). Soil structure dynamics is greatly impacted by natural processes such as wetting-drying and freeze-thaw cycles, and biological activity (root proliferation, soil fauna bioturbation) (e.g. Dexter, 1991). The different stages (Fig. 3) may be approached with different theoretical frameworks; for example, soil in condition directly after tillage may be best characterized as a granular matter, while soil in condition after compression or after intense aggregate coalescence may be best described as a continuum material. Furthermore, the question of whether a soil is a discrete or a continuum medium may be a question of scale, as illustrated in Fig. 9.

Models to describe the deformation of aggregates (as illustrated in Fig. 3) were developed by Ghezzehei and Or $(2000,2001)$ as mentioned in Section 2.1.3. These models take into account strain rate dependent soil properties and the rate of energy dissipation due to deformation and consider the geometry of aggregates, and can therefore describe the dynamics of the soil pore space and hence the evolution of gas and water transport properties (Eggers et al., 2006), i.e. link deformation and pore size distribution (e.g. Leij et al., 2002). Future developments of these approaches could include the representation of more complex pore/aggregate geometries and aggregate arrangements, and treatment of large strains up to total pore closure (Or and Ghezzehei, 2002; Berli et al., 2006).

Modelling of the transition of subsets of micro-continua to create another continuum region with distinct properties is a nonroutine exercise in continuum mechanics. The poro-geomechanics processes that will lead to the creation of a soil continuum from a collection of soil aggregates is quite complex since the mechanics 


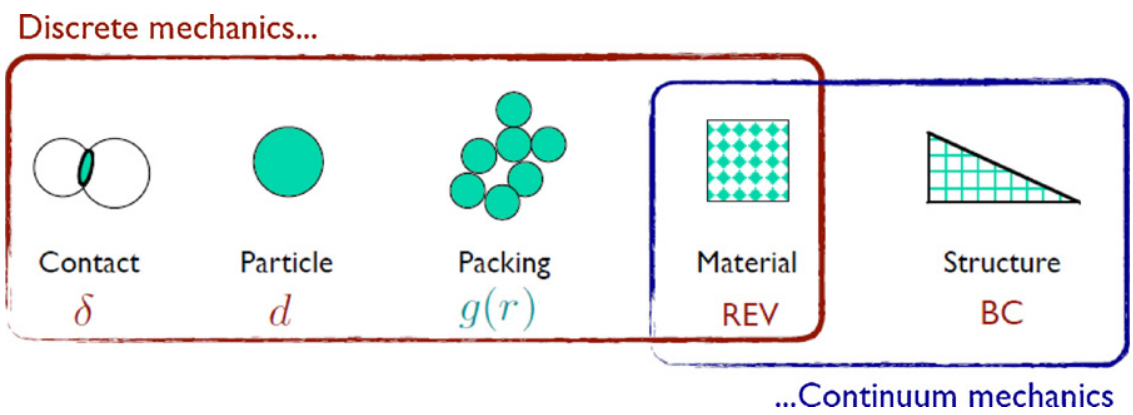

Fig. 9. Discrete to continuum as a function of scale.

can involve very large irreversible strains with reversible, irreversible and time-dependent material phenomena and moving boundary type interfaces (Selvadurai and Ghiabi, 2008; Selvadurai, 2011). In order to describe the transition from one stage to the next, or to characterize soil at an intermediate stage (Fig. 3), we suggest applying a combination of different approaches. DEM and FEM could be combined to explore the mechanical behaviour of agricultural soils. For example, structured agricultural soils could be represented by a collection of macroscopic particles (aggregates) characterized by their size, shape, strength and relative friction and cohesion, i.e. as granular systems, while each macroscopic particle could be considered as an idealized continuous region (Peron et al., 2009). The combination of DEM and FEM approaches can be done in two ways: (a) through a real combination, where the macrostructure is represented by a packing of distinct elements and the mechanical behaviour of these distinct elements is described by FEM, or (b) indirectly by using the results of a DEM analysis at the micro scale, to parameterize a FEM at the macro scale. It would be utopia to reproduce all processes occurring in soils during deformation, even with a complex combination of various theoretical approaches. However, the combined modelling could help identifying the main drivers that influence the mechanical behaviour of a soil.

Regardless of the approach, all models must be validated by experiments under well-controlled conditions. Because the process of deformation of structured, unsaturated soil is complex, simple experiments and simplified geometries are often required. Experiments could range from an arrangement of glass beads to beds of soil aggregates. Such experiments are not only needed for the purpose of validation of numerical models, but they also provide insights on soil deformation at the aggregate scale, and may form the basis for development of analytical solutions. Beside the intrinsic value of analytical solutions, analytical solutions are used for validation of numerical models, and to identify limits (e.g. analytical solutions for elastic material) of numerical solutions.

Research efforts will continue to move towards better quantification of soil structure, which can support the development of a structure-based soil mechanics framework. Advances in non-destructive imaging combined with finite and discrete element modelling will foster these developments (Sections 3 and 4), improving our understanding of small scale compaction effects, e.g. on root growth (e.g. Kirby and Bengough, 2002) and, in turn the effect of root growth on rhizosphere compaction (Aravena et al., 2011; Berli et al., 2011).

Describing and quantifying dynamic soil stress-strain behaviour will remain an important issue. It has been noted by several researchers that the macroscopic (e.g. at the size of a core sample, i.e. at the dm scale) stress-strain behaviour of agricultural soil is poorly described and understood (see e.g. Keller et al., 2011). This could be due to the hierarchical nature of soil structure, which is expressed in the scale-dependency of soil mechanical properties (Dexter, 1988) as illustrated in Fig. 9. Consequently, soil mechanical behaviour at a certain hierarchical level cannot be understood without knowledge of the mechanical behaviour of the adjacent lower hierarchical order. Therefore, experiments and modelling at scales smaller than the macroscopic scale are needed in order to understand the soil mechanical behaviour at the macroscopic scale (e.g. soil core or pedon scale). Discrete element methods can integrate such scale-dependent information and may therefore offer potential new approaches to soil compaction modelling.

\subsection{Mechanical deformation as a time (rate)-dependent process}

No comprehensive mechanical theory for agricultural and forest soils is currently available (see Section 2.1). One reason is the different time scales for agricultural/forestry types of loading compared to many civil engineering types of loading. In classical geomechanics the applied load is typically static and last for a long time (although we note that dynamic loading processes occur in geomechanical applications, such as impacts on railway tracks and roads, or earthquakes). In agricultural and forest soil mechanics, however, loads are highly dynamic, lasting from a fraction of a second (soil-tool interaction during soil tillage, loading at the soil surface by a tyre) to a few minutes (particularly in forestry, see e.g. Horn et al., 2004). Furthermore, loads can change significantly during operations (e.g. Horn et al., 2004).

As shown by Ghezzehei and Or (2001) soil deformation at equal load magnitude but different load duration is very different: the shorter the loading rate, the larger the elastic component and the smaller the viscous (permanent) component of the total strain. Dynamic aspects of soil deformation using concepts of rheology (e.g. Vyalov, 1986) have been considered by Or and co-workers (see references given in Section 2.1.3). Concurrently, efforts have been made to more realistically simulate loading by agricultural tyres by means of "classical" soil mechanics tests on undisturbed samples, by using shorter loading times (e.g. Keller et al., 2004) or by applying cyclic loading (e.g. Peth et al., 2010a). Although loading rates of these tests were much higher (and conversely, loading times much shorter) than in geomechanical applications, they were still considerably lower than in situ loading rates exerted by agricultural tyres (e.g. Keller and Lamandé, 2010). Furthermore, stress is applied in a pre-defined direction in soil mechanics laboratory tests (e.g. vertical stress application in oedometer tests), while the directions of the principal stresses are not constant during loading by a tyre.

Seismic methods (Sections 2.3 and 4.3) are fast and nondestructive. Therefore, they are potentially useful for studying dynamic soil deformation in situ, and could be combined with measurements/soil mechanical tests as outlined above. A starting point and promising approach will be to combine rheometric measurements and seismic analyses, which can be performed in overlapping stress and frequency domains. However, beyond empirical, the parallel development of a comprehensive theoretical 
basis will be essential, too. The potential use of seismic methods in soil compaction research is further addressed in Section 5.4.

We propose that research efforts to combine soil rheology and "classical" soil mechanics should be undertaken, towards a (theoretical) soil mechanical framework that includes all nonlinear, visco-elastic and plastic aspects and that could be applied to tie together the soil properties observed at different time and stress scales.

\subsection{Visualization of soil structure and soil deformation}

Modelling is useful to better understand the mechanical behaviour of soils, but model simulations have to be validated by (simple) experiments. During such experiments, soil structure and soil deformation before (initial state), during (e.g. at various stress application/loading steps) and after compression (final state) can today be visualized with the help of non-destructive measuring techniques (see Section 4). Recent technological advances in nondestructive measurement techniques offer new insight into soil architecture. Three-dimensional images could be used in studies on the mechanical behaviour of a soil to characterize particle arrangements and initial conditions for theoretical considerations on beds of spheres/aggregates (e.g. Ghezzehei and Or, 2000, 2001; Eggers et al., 2006, 2007; Berli et al., 2008); to obtain the deformation field or to identify how pores close during compaction (Peth et al., 2010b). The study by Peth et al. (2010b) revealed the generation of new structural macropores by capillary contraction as well as a simultaneous closure of cracks by plastic flow and initiation of shear fractures upon mechanical loading, underlining the dynamics of pore spaces upon changes in stress states. Since strain derived from digital image correlation can be localized within a sample domain (Fig. 8), such data could potentially be implemented in 3D finite element models to estimate local mechanical material properties. In addition, finite element meshes could be generated based on $\mu \mathrm{CT}$ data in order to simulate the influence of soil structure on stress distribution and hence the deformation process using realistic, "measured" architectures. On the other hand, structural changes simulated by mechanical models could be compared to actual deformation measured by $\mu \mathrm{CT}$ at the same boundary conditions, in turn providing validation data for models. As described in Sections 4.1 and 4.2, visualization of the soil architecture at the micro and aggregate scale is possible by means of X-ray (micro)tomography (CT and $\mu \mathrm{CT}$ ) and scanning electron microscopy (SEM). The different techniques apply to different scales: SEM at smallest scale ( $\mu \mathrm{m}$ scale), and CT at slightly larger scale $(\mu \mathrm{m}-\mathrm{mm})$. However, SEM does not allow for repeated measurements (e.g. same sample before, during and after compaction), due to sample preparation (Section 4.2). On the other hand, it does allow for the distinction between soil constituents (clay minerals, fungal hyphae, micro roots, fibres, etc.) and therefore the assessment of micromechanical properties (Markgraf, 2011).

\subsection{Linking seismic measurements to soil mechanical properties}

Potentially, seismic techniques allow non-destructive measurements at the pedon scale $(\mathrm{cm}, \mathrm{m})$ and in situ, in contrast to laboratory methods such as CT and SEM that work on soil core and aggregate $(\mathrm{mm}, \mathrm{cm})$ samples collected in the field.

There are a number of questions to be looked at in more detail if the seismic method is to be adapted for investigating soil structure and compaction:

- Which elastic soil parameters can be deduced from seismic measurements and which of them can be used to characterize soil mechanical properties and compaction in particular?
- Seismic waves are transient phenomena lasting only small fractions of a second and deforming the subsurface by "infinite" small elastic strains at frequencies of typically $10-100 \mathrm{~Hz}$. How can the resulting elastic soil constants, or corresponding wave velocities, be related to the classical soil mechanical properties resulting from measurements (soil mechanics tests such as uniaxial compression tests, shear tests or triaxial tests) where rather static and large "finite" strains are applied?

- Considering that the existing seismic methods have been designed to investigate deeper and thicker geological layers than soil, how can we achieve an adequately high horizontal and depth resolution with seismics? And can we develop seismic instruments capable of mapping larger agricultural areas in an economical way?

Indeed, there are only vague answers to most of these questions because the corresponding research is only in its infancy. However, the questions provide an orientation in which the research should be directed.

Because the propagation of seismic waves is related to very small strains, seismic wave velocity is related to the elastic material properties, i.e. elastic moduli. Attenuation of seismic waves is related to the viscous material properties. Therefore, at very low frequencies, analogies can be made between the attenuation of shear wave velocity obtained from seismic measurements and the visco-elastic shear modulus measured with a rheometer (Rabbel et al., unpublished).

Seismic measurements could be combined with visualization techniques on soil samples in the laboratory (e.g. CT, see previous Section or Section 4) during classical soil mechanical measurements (e.g. uniaxial compression). Seismic measurements could yield elastic and viscous properties of the material, the elasto-plastic properties would be obtained from the soil mechanical tests, while the CT-images could reveal information on the soil structure and the location of deformation (see previous Section). However, the relationships between the visco-elastic properties and seismic wave propagation need to be established first.

The largest contribution of seismic methods in soil compaction research may be seen in the possibility to conduct in situ investigations. Because seismic measurements are non-destructive and fast, they could reveal insight into the dynamic soil response to wheel loading. An example is presented in Fig. 10, which shows the seismic wave velocity at various depths below a wheel rut before, during and after loading with a tyre (Carizzoni et al., unpublished data). A highly dynamic behaviour is observed,

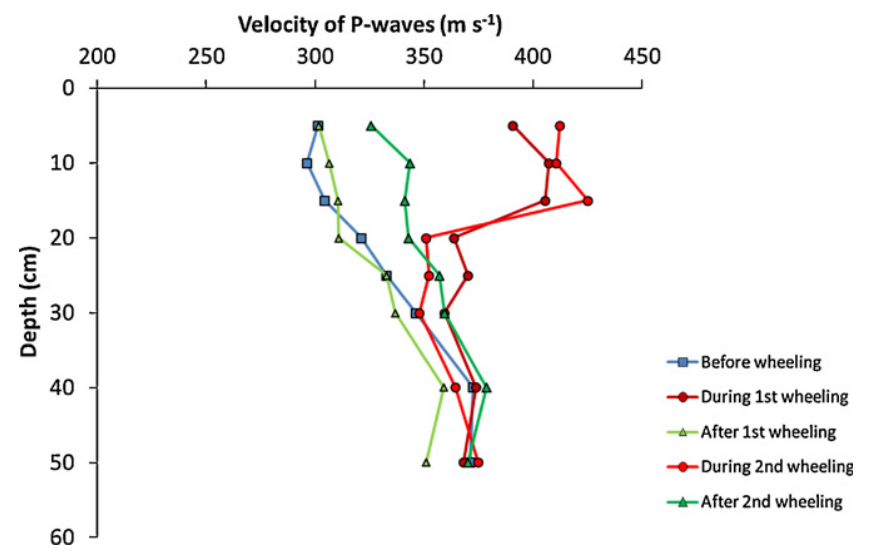

Fig. 10. Velocity of seismic waves across a wheel rut at various depths before, during and after loading with an agricultural tyres (load: $58 \mathrm{kN}$; tyre: 800/65R32) on a clay loam soil (Carizzoni et al., unpublished data). The seismic method is described in Carizzoni (2007). 
and the effects of repeated loading are visible. Such information would be difficult to obtain with traditional soil mechanical methods.

The use of seismic waves to obtain the plastic properties of an agricultural soil might be very challenging because a very high frequency source has to be used, and its reflection might be difficult to detect. However, qualitative agreements between seismic velocity of surface waves and soil strength parameters, e.g. penetration resistance (Ayres and Theilen, 1999), are promising.

A useful application of seismic methods in soil compaction research is in the characterization of the mechanical properties of a soil at the field scale. In our attempts to reduce the risk of soil compaction by agricultural field traffic, it is important to consider not only a soil sample (decimetres) or a soil pedon (metres), but a whole field (hectares). However, most research on prevention of soil compaction with some mechanical basis does not go beyond the size of a soil profile. This is because usually only the wheel rut is considered. Seismic methods could provide the basis for assessing vulnerability of soil compaction at the field scale and for recommending site-specific management with regard to soil compaction.

\section{Conclusions}

Several disciplines deal with stress transmission and deformation processes in porous media, but the theoretical frameworks and modelling approaches may differ. The description of soil deformation processes in arable soil typically relies on theories from conventional soil mechanics (e.g. foundation engineering), despite significant differences between agricultural and geotechnical applications that have important consequences for the mechanical behaviour of soil. The most important are that stresses applied by agricultural tyres/tracks and implements are dynamic and the loading time is short, and that arable soils are typically unsaturated and structured. Moreover, soil structure is scaledependent and dynamic, and a soil may evolve from a material that resembles a granular material (e.g. a seedbed) to a material that is best described as a continuum due to overburden, external stresses, and capillary forces.

Therefore, we believe that approaches from granular materials science (e.g. distinct element modelling), in combination with classical continuum mechanics (e.g. finite element modelling), could advance our understanding of the mechanical behaviour of arable soil.

Recent technological advances in non-destructive measurement techniques such as X-ray computed tomography offer new insight into soil architecture and allow for visualization of soil deformation, which could be used for the development and validation of new approaches in soil compaction modelling. Seismic methods could be used to better understand the dynamics of soil mechanical processes, especially in in situ investigations. Non-invasive measurement techniques in combination with numerical modelling could be a powerful tool for characterizing the stress-strain relationships of soils.

Soil structure can be described as a hierarchy, where compound particles (clods, aggregates, micro-aggregates, etc.) of a certain hierarchical order are a complex of compound particles from the next lower order. One consequence of this concept is that soil mechanical properties are scale-dependent. We suggest that the mechanical behaviour of a soil at one specific hierarchical level cannot be fully understood without knowledge of the mechanical behaviour of the next lower hierarchical order. The non-invasive measuring techniques reviewed in this paper cover various scales, from the micro scale (scanning electron micoscropy, $\mu \mathrm{CT}$ ) to the meso scale (CT) to the macro scale (CT, seismic methods). Similarly, theories and modelling approaches discussed in this paper could be associated with different scales: micro scale (rheology), aggregate to macro scale (granular approach), and macro to pedon scale (continuum mechanics). Therefore, the combination of these techniques and theoretical frameworks is a promising way towards a better understanding of the mechanical behaviour of arable soil.

\section{Author contributions}

All authors contributed to discussions that resulted in this paper. T.K. and M.L. conceptualized the manuscript and prepared Sections 1, 5 and 6; M.B. prepared Sections 2.1.1 and 2.1.2; W.B. T.K., D.O. prepared Section 2.1.3; A.P.S.S. prepared Sections 2.2 and 3.1; W.R. prepared Sections 2.3 and 4.3; J.-Y.D., F.R. and J.R. prepared Sections 2.4 and 3.3; S.P. prepared Sections 3.2 and 4.1; W.B. prepared Section 4.2. All authors revised the manuscript.

\section{Acknowledgements}

This paper is an output from the International Exploratory Workshop on Soil Compaction Modelling that was held 12-13 October 2010 at the Agroscope Research Station ART in Zurich (Switzerland), which was convened by the first and the second author of this paper. We would like to thank Marco Carizzoni (University of Berne, $\mathrm{CH}$ ), Feto E. Berisso (Aarhus University, DK), Alexander Puzrin (Swiss Federal Institute of Technology ETH, CH), Per Schjønning (Aarhus University, DK), Jan van den Akker (Alterra Wageningen, NL) and Peter Weisskopf (Agroscope ART, $\mathrm{CH}$ ) for valuable discussions during the workshop. The workshop received financial support from the Swedish Research Council for Environment, Agricultural Sciences and Spatial Planning (Formas), the International Soil Tillage Research Organization (ISTRO) and Wille Geotechnik APS GmbH, Göttingen (D), which is gratefully acknowledged. The editorial assistance of Sally Selvadurai, Assist-Ed, Montreal is gratefully acknowledged.

\section{References}

Abu-Hamdeh, N.H., Reeder, R.C., 2003. A nonlinear 3D finite element analysis of the soil forces acting on a disk plow. Soil Tillage Research 74, 115-124.

Alaoui, A., Lipiec, J., Gerke, H.H., 2011. A review of the changes in the soil pore system due to soil deformation: a hydrodynamic perspective. Soil Tillage Research 115-116, 1-15.

Al Hagrey, S.A., Meissner, R., Werban, U., Rabbel, W., Ismail, A., 2004. Hydro-, biogeophysics. The Leading Edge 23, 670-674.

Allred, B.J., Ehsani, M.R., Daniels, J.J., 2008. General considerations for geophysical methods applied to agriculture. In: Allred, B.J., Daniels, J.J., Ehsani, M.R. (Eds.), Handbook of Agricultural Geophysics. CRC Press, London, pp. 3-16.

Alonso, E.E., Gens, A., Josa, A., 1990. A constitutive model for partially saturated soils. Géotechnique 40, 405-430.

Aravena, J.N.E., Berli, M., Ghezzehei, T.A., Tyler, S.W., 2011. Effects of root-induced compaction on rhizosphere hydraulic properties - X-ray microtomography imaging and numerical simulations. Environmental Science \& Technology 45 425-431.

Ayres, A., Theilen, F., 1999. Relationship between P- and S-wave velocities and geological properties of near-surface sediments of the continental slope of the Barents Sea. Geophysical Prospecting 47, 431-441.

Azéma, E., Radjai, F., Saussine, G., 2009. Quasistatic rheology, force transmission and fabric properties of a packing of irregular polyhedral particles. Mechanics of Materials 41, 729-741.

Bailey, A.C., VandenBerg, G.E., 1968. Yielding by shear and compaction in unsaturated soils. Transactions of the American Society of Agricultural Engineers 11, 307-311 317.

Baker, G.S., Steeples, D.W., Schmeissner, C., 1999. In-situ, high-frequency P-wave velocity measurements within $1 \mathrm{~m}$ of the earth's surface. Geophysics 64, 323-325.

Baver, L.D., 1940. Soil Physics. John Wiley \& Sons, New York.

Bear, J., Verruijt, A., 1987. Modeling Groundwater Flow and Pollution. D. Reidel Publishing Company, Dordrecht, $414 \mathrm{pp}$.

Bekker, M.G., 1956. Theory of Land Locomotion. The University of Michigan Press, Ann Arbor.

Bekker, M.G., 1969. Introduction to Terrain-Vehicle Systems. The University of Michigan Press, Ann Arbor. 
Berli, M., Accorsi, M.L., Or, D., 2006. Size and shape evolution of pores in viscoplastic matrix under compression. International Journal for Numerical and Analytical Methods in Geomechanics 30, 1259-1281.

Berli, M., Carminati, A., Ghezzehei, T.A., Or, D., 2008. Evolution of unsaturated hydraulic conductivity of aggregated soils due to compressive forces. Water Resource Research 44, W00C09.

Berli, M., Or, D., 2006. Deformation of pores in viscoplastic soil material. International Journal of Geomechanics 6, 108-118.

Berli, M., Ruiz, S.A., Aravena, J.E., Bolduc, L., Ghezzehei, T.A., Cook, D.P., Mandava, A.K., Regentova, E.E., Menon, M., Nico, P., Tyler, S.W., Young, M.H., 2011. Simulating rhizosphere structure alterations using finite element calculations. In: European Geoscience Union General Assembly, EGU, Vienna, Austria, pp. EGU2011-EGU13530.

Besson, A., Cousin, I., Samouëlian, A., Boizard, H., Richard, G., 2004. Structural heterogeneity of the soil tilled layer as characterized by $2 \mathrm{D}$ electrical resistivity surveying. Soil Tillage Research 79, 239-249.

Biot, M.A., 1941. General theory of three-dimensional consolidation. Journal of Applied Physics 12, 155-164.

Bishop, A.W., 1959. The principle of effective stress. Teknisk Ukeblad 106, 859-863.

Boussinesq, J., 1885. Application des potentiels à l'étude de l'équilibre et des mouvements des solides élastiques. Gauthier-Villars, Paris, 30 pp.

Brinkgreve, R.B.J., 2002. PLAXIS Version 8, Material Models Manual. Balkema, The Netherlands, ISBN: 9058095088.

Calvetti, F., Combe, G., Lanier, J., 1997. Experimental micromechanical analysis of a 2D granular material: relation between structure evolution and loading path. Mechanics of Cohesive Frictional Materials 2, 121-163.

Carizzoni, M., 2007. Die Ausbreitung von akustischen Wellen zur Untersuchung struktureller Eigenschaften von Landwirtschaftsböden (In German with English summary). Dissertation University of Bern, Switzerland, 157 pp.

Casagrande, A., 1936. The determination of pre-consolidation load and its practical significance. In: Proc. Int. Conf. Soil Mechanics and Foundation Engineering, Vol. 3, 22-26 June, Harvard University, Cambridge, Mass, USA, pp. 60-64.

COM, 2006. 232 final (http://ec.europa.eu/environment/soil/pdf/com_2006_0232_ en.pdf).

Corwin, D.L., 2008. Past, present and future trends of soil electrical conductivity measurement using geophysical methods. In: Allred, B.J., Daniels, J.J., Ehsani, M.R. (Eds.), Handbook of Agricultural Geophysics. CRC Press, London, pp. 3-16.

Coulomb, C.A., 1776. Essai sur une application des règles de maximis et minimis à quelques problèmes de statique, relatifs à l'architecture. Mémoires de mathématiques et de physique présentés à l'Académie royale des sciences par divers savants 7, 343-382.

Cundall, P.A., Strack, O.D.L., 1979. A discrete numerical model for granular assemblies. Géotechnique 29, 47-65.

da Cruz, F., Emam, S., Prochnow, M., Roux, J.N., Chevoir, F., 2005. Rheophysics of dense granular materials: discrete simulation of plane shear flows. Physical Review E 72, 021309.

Da Silva, M., Rajchenbach, J., 2000. Stress transmission through a model system of cohesionless elastic grains. Nature 406, 708-710.

Danno, K., Kimura, M., 2009. Evaluation of long-term displacements of pile foundation using coupled FEM and centrifuge model test. Soils and Foundations 49, 941-958.

Davis, R.O., Selvadurai, A.P.S., 1996. Elasticity and Geomechanics. Cambridge University Press, Cambridge.

Davis, R.O., Selvadurai, A.P.S., 2002. Plasticity and Geomechanics. Cambridge University Press, Cambridge.

Défossez, P., Richard, G., 2002. Models of soil compaction due to traffic and their evaluation. Soil Tillage Research 67, 41-64.

Delenne, J.-Y., El Youssoufi, M.S., Cherblanc, F., Bénet, J.-C., 2004. Mechanical behavior and failure of a cohesive granular material. International Journal for Numerical and Analytical Methods in Geomechanics 28, 1577-1594.

Delerue, J.P., Perrier, E., Yu, Z.Y., Velde, B., 1999. New algorithms in 3D image analysis and their application to the measurement of a spatialized pore size distribution in soils. Physics and Chemistry of the Earth, Part A 24, 639-644.

Desai, C.S., Siriwardane, H.J., 1984. Constitutive Laws for Engineering Materials: With Emphasis on Geologic Materials. Prentice-Hall, Englewood Cliffs, N.J.

Desrues, J., Viggiani, G., Bésuelle, P., 2006. Advances in X-ray Tomography for Geomaterials. John Wiley \& Sons, 452 pp.

Dexter, A.R., 1988. Advances in characterization of soil structure. Soil Tillage Research 11, 199-238.

Dexter, A.R., 1991. Amelioration of soil by natural processes. Soil Tillage Research 20, $87-100$

Eggers, C.G., Berli, M., Accorsi, M.L., Or, D., 2007. Permeability of deformable soft aggregated earth materials: from single pore to sample cross-section. Water Resource Research 43, W08424

Eggers, C.G., Berli, M., Accorsi, M.L., Or, D., 2006. Deformation and permeability of aggregated soft earth materials. Journal of Geophysical Research - Solid Earth 111, B10204.

El Hadji Bouya, A., Clamond, D., Fraysse, N., Rajchenbach, J., 2011. Response of a noncohesive packing of grains to a localized force: deviation from continuum elasticity. Physical Review E 83, 021304.

Estrada, N., Taboada, A., Radjai, F., 2008. Shear strength and force transmission in granular media with rolling resistance. Physical Review E 78, 021301.

Fillunger, P., 1913. Der Auftrieb in Talsperren. Österreichische Wochenschrift für den öffentlichen Baudienst 19, 532-556 567-570.

Fredlund, D.G., Rahardjo, H., 1993. Soil Mechanics for Unsaturated Soils. John Wiley \& Sons, New York, 517 pp.
Fricke, S., Schön, J., 1999. Praktische Bohrlochgeophysik. Enke, Stuttgart, 254 p.

Fröhlich, O.K. 1934. Druckverteilung im Baugrunde [Pressure Distribution in Foundation Soils]. Springer Verlag, Wien, Austria, 183 pp.

Gantzer, C.J., Anderson, S.H., 2002. Computed tomographic measurement of macroporosity in chisel-disk and no-tillage seedbeds. Soil Tillage Research 64, 101-111.

Gerke, H.H., 2006. Preferential flow description for structured soils. Journal of Plant Nutrition and Soil Science 169, 382-400.

Ghezzehei, T.A., Or, D., 2001. Rheological properties of wet soils and clays under steady and oscillatory stresses. Soil Science Society of America Journal 65 624-637.

Ghezzehei, T.A., Or, D., 2000. Dynamics of soil aggregate coalescence governed by capillary and rheological processes. Water Resource Research 36, 367-379.

Ghezzehei, T.A., Or, D., 2003. Stress-induced volume reduction of isolated pores in wet soil. Water Resource Research 39, 1067.

Goldstein, J., 2003. Scanning Electron Microscopy and X-ray microanalysis, 3rd ed. Springer, New York.

Gräsle, W., Baumgartl, T., Horn, R., Richards, B.G., 1995. Interaction between soil mechanical properties of structured soils and hydraulic process - theoretica fundamentals of a model. In: Alonso, E.E., Delage, P. (Eds.), Proc. 1st Int. Conf. Unsaturated Soils UNSAT'95, 6-8 Sept. 1995, Paris, France. Balkema 2, pp. 719-724.

Griffiths, D.V., Lane, P.A., 1999. Slope stability analysis by finite elements. Géotechnique 49, 387-403.

Gysi, M., Klubertanz, G., Vulliet, L., 2000. Compaction of an Eutric Cambisol under heavy wheel traffic in Switzerland-field data and modelling. Soil Tillage Research 56, 117-129.

Hagin, P.N., Zoback, M.D., 2004. Viscous deformation of unconsolidated reservoir sands - Part 2: linear viscoelastic models. Geophysics 69, 742-751.

Hartge, K.H., Sommer, C., 1980. The effect of geometric patterns of soil structure on compressibility. Soil Science 130, 180-185.

He, X., Ren, L., 2009. An adaptive multiscale finite element method for unsaturated flow problems in heterogeneous porous media. Journal of Hydrology 374 $56-70$

Hettiaratchi, D.R.P., 1987. A critical state soil mechanics model for agricultural soils Soil Use Manangement 3, 94-105.

Horgan, G.W., 1998. Mathematical morphology for analysing soil structure from images. European Journal of Soil Science 49, 161-173.

Horn, R., 1993. Mechanical properties of structured unsaturated soils. Soil Technology $6,47-75$

Horn, R., Richards, B.G., Gräsle, W., Baumgartl, T., Wiermann, C., 1998. Theoretical principles for modelling soil strength and wheeling effects: a review. Journal of Plant Nutrition and Soil Science 161, 333-346.

Horn, R., Vossbrink, J., Becker, S., 2004. Modern forestry vehicles and their impacts on soil physical properties. Soil Tillage Research 79, 207-219.

Horn, R., Way, T., Rostek, J., 2003. Effect of repeated tractor wheeling on stress/strain properties and consequences on physical properties in structured arable soils. Soil Tillage Research 73, 101-106.

Jean, M., 1999. The non-smooth contact dynamics method. Computer Methods in Applied Mechanics and Engineering 177, 235-257.

Jégou, D., Brunotte, D., Rogasik, H., Capowiez, Y., Diestel, H., Schrader, S., Cluzeau, D. 2002. Impact of soil compaction on earthworm burrow systems using X-ray computed tomography. European Journal of Soil Biology 38, 329-336.

Keller, T., Arvidsson, J., Dawidowski, J.B., Koolen, A.J., 2004. Soil precompression stress. II. A comparison of different compaction tests and stress-displacement behaviour of the soil during wheeling. Soil Tillage Research 77, 97-108.

Keller, T., Lamandé, M., 2010. Challenges in the development of analytical soil compaction models. Soil Tillage Research 111, 54-64.

Keller, T., Lamandé, M., Schjønning, P., Dexter, A.R., 2011. Analysis of soil compression curves from uniaxial confined compression tests. Geoderma 163, 13-23.

Kim, H., Anderson, S.H., Motavalli, P.P., Gantzer, C.J., 2010. Compaction effects on soil macropore geometry and related parameters for an arable field. Geoderma $160,244-251$

Kirby, J.M., 1994. Simulating soil deformation using a critical-state model: I. Laboratory tests. European Journal of Soil Science 45, 239-248.

Kirby, J.M., Bengough, A.G., 2002. Influence of soil strength on root growth: experiments and analysis using a critical-state model. European Journal of Soil Science 53, 119-128.

Kirsch, R., 2010. Petrophysical properties of permeable and low-permeable rocks. In: Kirsch, R. (Ed.), Groundwater Geophysics. 2nd ed. Springer-Verlag, Berlin, pp. 1-22.

Kremer, J., Wolf, B., Matthies, D., 2002. Verformungsverhalten künstlicher Makroporen unter variierenden Druck- und Bodenfeuchtebedingungen. Journal of Plant Nutrition and Soil Science 165, 627-633.

Kushwaha, R.L., Chi, L., Shen, J., 1993. Analytical and numerical models for predicting soil forces on narrow tillage tools - a review. Canadian Agricultural Engineering 35, 183-193.

Lamandé, M., Schjønning, P., 2011. Transmission of vertical stress in a real soil profile. Part III. Effect of soil water content. Soil Tillage Research 114, 78-85.

Langmaack, M., Schrader, S., Rapp-Bernhardt, U., Kotzke, K., 1999. Quantitative analysis of earthworm burrow systems with respect to biological soil-structure regeneration after soil compaction. Biology and Fertility of Soils 28, 219-229.

Leij, F.J., Ghezzehei, T.A., Or, D., 2002. Modeling the dynamics of the soil pore-size distribution. Soil Tillage Research 64, 61-78.

Lück, E., Gebbers, R., Ruelmann, J., Sprangenberg, U., 2009. Electrical conductivity mapping for precision farming. Near Surface Geophysics 7, 15-25. 
Majmudar, T.S., Behringer, R.P., 2005. Contact force measurements and stressinduced anisotropy in granular materials. Nature 435, 1079-1082.

Mansouri, M., Delenne, J.-Y., El Youssoufi, M.S., Seridi, A., 2009. A 3D DEM-LBM approach for the assessment of the quick condition for sands. Comptes Rendus Mécanique 337, 675-681.

Markgraf, W., 2011. Rheology in soils. In: Glinski, J., Horabik, J., Lipiec, J. (Eds.), Encyclopedia of Agrophysics. Springer, Amsterdam, pp. 700-704.

Markgraf, W., Horn, R., 2006. Rheometry in soil mechanics: microstructural changes in a calcaric gleysol and a dystric planosol. In: Horn, R., Fleige, H., Peth, S., Peng X.H. (Eds.), Sustainability - Its Impact on Soil Management and Environment, 38. Catena Verlag, Adv. Geoecol, pp. 47-58.

Markgraf, W., Horn, R., 2009. Chapter 9 - Rheological investigations in soil micro mechanics: measuring stiffness degradation and structural stability on a particle scale. In: Gragg, L.P., Cassell, J.M. (Eds.), Progress in Management Engineering. Nova Science Publishers, Hauppauge, NY.

Markgraf, W., Horn, R., Peth, S., 2006. An approach to rheometry in soil mechanics: structural changes in bentonite, clayey and silty soils. Soil Tillage Research 91 , $1-14$.

Markgraf, W., Watts, C.W., Whalley, W.R., Hrkac, T., Horn, R., 2012. Influence of organic matter on rheological properties of soil. Applied Clay Science 64, 25-33.

McNamara, S., Young, W.R., 1992. Inelastic collapse and clumping in a one-dimensional granular medium. Physics of Fluids A 4, 496-504.

Mikita, V., Kovacs, B., Foldes, T., 2009. The use of computer tomography for evaluation of the compaction of loose, agricultural soils. Cereal Research Communications 37, 427-430.

Misra, A., Huang, S., 2009. Micromechanics based stress-displacement relationships of rough contacts: numerical simulation under combined normal and shear loading. Computer Modeling in Engineering and Science 52, 197-216.

Moreau, J.J., 1994. Some numerical methods in multibody dynamics: application to granular materials. European Journal of Mechanics A/Solids 4, 93-114.

Nelson, I., 1970. Investigation of ground shock effects in non-linear hysteretic media. Report 1. Modelling the behaviour of a real soil. Paul Weiblinger Consulting Engineers, US Army Waterways Experiment Station.

Or, D., 1996. Wetting induced soil structural changes: the theory of liquid phase sintering. Water Resource Research 32, 3041-3049.

Or, D., Ghezzehei, T.A., 2002. Modeling post tillage structural dynamics in aggregated soils: a review. Soil Tillage Research 64, 41-59.

O'Sullivan, M.F., Robertson, E.A.G., 1996. Critical state parameters from intact samples of two agricultural topsoils. Soil Tillage Research 39, 161-173.

Pedrotti, A., Pauletto, E.A., Crestana, S., Holanda, F.S.R., Cruvinel, P.E., Vaz, C.M.P., 2005. Evaluation of bulk density of Albaqualf soil under different tillage systems using the volumetric ring and computerized tomography methods. Soil Tillage Research 80, 115-123.

Peron, H., Delenne, J.-Y., Laloui, L., El Youssoufi, M.S., 2009. M. S. discrete element modelling of drying shrinkage and cracking of fine-grained soils. Computers and Geotechnics 36, 61-69.

Petersen, H., Rabbel, W., Horn, R., Fleige, H., 2005. Applicability of geophysical prospecting methods for mapping of soil compaction and variability of soil texture on farm land. Journal of Plant Nutrition and Soil Science 168, 1-12.

Peth, S., 2011. Noninvasive quantification of 3D pore space structures in soils. In: Glinski, J., Horabik, J., Lipiec, J. (Eds.), Encyclopedia of Agrophysics. Springer, Berlin, pp. 516-519.

Peth, S., Nellesen, J., Fischer, G., Tillmann, W., Horn R., 2012. Quantifying and modeling soil structure dynamics. In: Logsdon, S., Horn, R., Berli, M. (Eds.), Advances in Modeling Agricultural Systems: Trans-disciplinary Research, Synthesis, Modeling, and Applications. ASA-SSSA-CSSA book series Vol. 4 (http:// dx.doi.org/10.2134/advagricsystmodel3.c6), in press.

Peth, S., Horn, R., Beckmann, F., Donath, T., Fischer, J., Smucker, A.J.M., 2008. Threedimensional quantification of intra-aggregate pore-space features using synchrotron-radiation-based microtomography. Soil Science Society of America Journal 72, 897-907.

Peth, S., Horn, R., Fazekas, O., Richards, B.G., 2006. Heavy soil loading and its consequences for soil structure, strength and deformation of arable soils. Journal of Plant Nutrition and Soil Science 169, 775-783.

Peth, S., Rostek, J., Zink, A., Mordhorst, A., Horn, R., 2010a. Soil testing of dynamic deformation processes of arable soils. Soil Tillage Research 106, 317-328.

Peth, S., Nellesen, J., Fischer, G., Horn, R., 2010b. Non-invasive 3D analysis of local soil deformation under mechanical and hydraulic stresses by $(\mu) C T$ and digital image correlation. Soil Tillage Research 111, 3-18.

Petrovic, A.M., Siebert, J.E., Rieke, P.E., 1982. Soil bulk density analysis in three dimensions by computed tomographic scanning. Soil Science Society of America Journal 46, 445-450.

Pietruszczak, S., 2010. Fundamentals of Plasticity in Geomechanics. CRC Press, Boca Raton, FL.

Pires, L.F., Bacchi, O.O.S., Reichardt, K., 2005. Gamma ray computed tomography to evaluate wetting/drying soil structure changes. Nuclear Instruments and Methods in Physics Research Section B: Beam Interactions with Materials and Atoms 229, 443-456.

Pires, L.F., Bacchi, O.O.S., Reichardt, K., 2007. Assessment of soil structure repair due to wetting and drying cycles through 2D tomographic image analysis. Soil Tillage Research 94, 537-545.

Pires, L.F., de Macedo, J.R., de Souza, M.D., Bacchi, O.O.S., Reichardt, K., 2003. Gamma-ray-computed tomography to investigate compaction on sewagesludge-treated soil. Applied Radiation and Isotopes: Including Data, Instrumentation, and Methods for Use in Agriculture, Industry, and Medicine 59, $17-25$.
Poulos, H.G., Davis, E.H., 1975. Elastic Solutions for Soil and Rock Mechanics. Wiley, New York

Rabbel, W., 2010. Seismic methods. In: Kirsch, R. (Ed.), Groundwater Geophysics. 2nd ed. Springer-Verlag, Berlin, pp. 23-83.

Radcliff, D.E., Simunek, J., 2010. Soil Physics with Hydrus. CRC Press, London, 373 pp.

Radjai, F., Dubois, F., 2011. Discrete-element Modeling of Granular Materials. John Wiley \& Sons, Berlin, 496 pp.

Radjai, F., Jean, M., Moreau, J.J., Roux, S., 1996. Force distributions in dense twodimensional granular systems. Physical Review Letters 77, 274.

Radjai, F., Roux, S., 2002. Turbulentlike fluctuations in quasistatic flow of granular media. Physical Review Letters 89, 064302.

Radjai, F., Roux, S., 2004. Contact dynamics study of 2D granular media: critical states and relevant internal variables. In: Hinrichsen, H., Wolf, D.E. (Eds.), The Physics of Granular Media. Wiley-Vch, Berlin, pp. 165-186.

Radjai, F., Wolf, D., Jean, M., Moreau, J.J., 1998. Bimodal character of stress transmission in granular packings. Physical Review Letters 90, 61.

Rankine, W.J.M., 1857. On the stability of loose earth. Philosophical Transactions of the Royal Society of London 147, 9-27.

Rankine, W.J.M., 1858. A Manual of Applied Mechanics. Richard Griffin \& Co., London \& Glasgow, pp. 640

Reiner, M., 1960. Lectures on Theoretical Rheology, 3rd ed. North-Holland Publishing Company, Amsterdam, The Netherlands, XVI+158 pp.

Richards, B.G., 1992. Modelling interactive load-deformation and flow processes in soils, including unsaturated and swelling soils. In: Pro. $6^{\text {th }}$ Australian-New Zealand Conf. Geomechanics, Christchurch, NZ, pp. 18-37.

Richards, B.G., Greacen, E.L., 1986. Mechanical stress on an expanding cylindrical root analogue in granular media. Australian Journal of Soil Research 24, 393-404

Richards, B.G., Peth, S., 2009. Modelling soil physical behaviour with particular reference to soil science. Soil Tillage Research 102, 216-224.

Rogasik, H., Onasch, I., Brunotte, J., Jegou, D., Wendroth, O., 2003. Assessment of soil structure using X-ray computed tomography. In: Mees, F., Swennen, R., van Geet, M., Jacobs, P. (Eds.), Applications of X-ray Computed Tomography in the Geosciences, 215. Geological Society of London, London, pp. 151-165.

Roscoe, K.H., Schofield, A.N., Wroth, C.P., 1958. On the yielding of soils. Géotechnique $8,22-53$.

Roux, S., Radjai, F., 2001. Statistical approach to the mechanical behaviour of granular media. In: Aref, H., Philips, J.W. (Eds.), Mechanics for a New Millenium. Kluwer, The Netherlands, pp. 181-196.

Sander, T., Gerke, H.H., Rogasik, H., 2008. Assessment of Chinese paddy-soil structure using X-ray computed tomography. Geoderma 145, 303-314.

Schäffer, B., Stauber, M., Mueller, T.L., Müller, R., Schulin, R., 2008a. Soil and macro-pores under uniaxial compression. I. Mechanical stability of repacked soil and deformation of different types of macro-pores. Geoderma $146,183-191$

Schäffer, B., Mueller, T.L., Stauber, M., Müller, R., Keller, M., Schulin, R., 2008b. Soil and macro-pores under uniaxial compression. II. Morphometric analysis of macropore stability in undisturbed and repacked soil. Geoderma 146, 175-182.

Schofield, A.N., Wroth, C.P., 1968. Critical State Soil Mechanics. McGraw-Hill, London.

Schön, J.H., 1996. Physical Properties of Rocks: Fundamentals and Principles of Petrophysics. Handbook of Geophysical Exploration, 18. Pergamon Press, Oxford.

Schrader, S., Rogasik, H., Onasch, I., Jegou, D., 2007. Assessment of soil structural differentiation around earthworm burrows by means of X-ray computed tomography and scanning electron microscopy. Geoderma 137, 378-387.

Selvadurai, A.P.S., 2012. On Fröhlich's result for Boussinesq's problem. In: Proc. 83rd Annual Meeting of the Gesellschaft für Angewandte Mathematik und Mechanik, Darmstadt, pp. 405-406.

Selvadurai, A.P.S., 2011. Compaction of multiphase geomaterials. Structural Longevity $5,69-76$

Selvadurai, A.P.S., Ghiabi, H., 2008. Consolidation of a soft clay composite: experimental results and computational estimates. Computer Modeling in Engineering and Science 23, 53-73.

Selvadurai, A.P.S., Nguyen, T.S., 1995. Computational modelling of isothermal consolidation of fractured media. Computers and Geotechnics 17, 39-73.

Sheriff, R.E., Geldart, L.P., 1995. Exploration Seismology. Cambridge University Press, New York.

Shmulevich, I., 2010. State of the art modeling of soil-tillage interaction using discrete element method. Soil Tillage Research 111, 41-53.

Söhne, W., 1951. Das mechanische Verhalten des Ackerbodens bei Belastungen, unter rollenden Rädern, sowie bei der Bodenbearbeitung. Grundlagen Landtechnik 1, 87-94.

Söhne, W., 1953. Druckverteilung im Boden und Bodenverformung unter Schlepperreifen. Grundlagen der Landtechnik 5, 49-63.

Söhne, W., 1958. Fundamentals of pressure distribution and soil compaction under tractor tires. Agricultural Engineering 39, 276-291.

Staron, L., Lajeunesse, E., 2009. Understanding how the volume affects the mobility of dry debris flows. Geophysical Research Letters 36, L12402.

Suyama, K., Imai, T., Ohtomo, H., Ohta, K., Ohishi, Y., 1983. Shallow seismic reflection exploration in soft ground using SH waves. SEG Expanded Abstracts, vol. 2. , http://dx.doi.org/10.1190/1.1827176 p. 103

Taboada, A., Chang, K.-J., Radjai, F., Bouchette, F., 2005. Rheology, force transmission and shear instabilities in granular media from biaxial numerical tests using the contact dynamics method. Journal of Geophysical Research 110, B09202. 
Taboada, A., Estrada, N., Radjai, F., 2006. Additive decomposition of shear strength in cohesive granular media from grain-scale interactions. Physical Review Letters 97, 098302.

Terzaghi, K., 1923. Die Berechnung der Durchlässigkeitsziffer des Tones aus der Verlauf der hydrodynamischen Spannungserscheinungen. Sitzungsbericht der Akademie der Wissenschaften in Wien, Mathematisch-Naturwissenschaftliche Klasse, Abteilung IIA. Akademie der Wissenschaften in Wien, Wien, pp. 125-138.

Terzaghi, K., 1925. Erdbaumechanik auf bodenphysikalischer Grundlage. Franz Deuticke, Wien.

Terzaghi, K., 1943. Theoretical Soil Mechanics. John Wiley \& Sons Inc, New York. Timoshenko, S.P., Goodier, J.N., 1970. Theory of Elasticity. McGraw-Hill, New York.

Topin, V., Delenne, J.-Y., Radjai, F., Brendel, L., Mabille, F., 2007. Strength and failure of cemented granular matter. The European Physical Journal E 23, 413-429.

Trautner, A., Arvidsson, J., 2003. Subsoil compaction caused by machinery traffic on a Swedish Eutric Cambisol at different soil water contents. Soil Tillage Research 73, 107-118

Truesdell, C.A., 1961. Stages in the development of the concept of stress. In: Problems in Mechanics Contributions in Honor of the 70th Birthday of Academician N.I. Muskhelishvili, Society for Industrial and Applied Mathematics, Philadelphia, PA, pp. 556-564.

Tsai, J.-C., Voth, G.A., Gollub, J.P., 2003. Internal granular dynamics, shear-induced crystallization, and compaction steps. Physical Review Letters 91, 064301.

Tuller, M., Vaz, C.M.P., Kulkarni, R., 2010. A new generation of high-resolution benchtop micro-CT scanners for application in soil science. In: de Jonge, L.W., Moldrup, P., Vendelboe, A.L. (Eds.), 1st Int. Conf. and Exploratory Workshop Soil Architecture and Physico-Chemical Functions CESAR, DJF Report December 2. pp. 391-394.

Uyanik, O., 2010. Compressional and shear-wave velocity measurements in unconsolidated top-soil and comparison of the results. International Journal of Physical Science 5, 1034-1039.

van der Kloster, E., van Egmont, F.M., Sonneveld, M.P.W., 2011. Mapping soil clay contents in Dutch marine districs using gamma-ray spectrometry. European Journal of Soil Science 62, 743-753.

van Ouwerkerk, C., Soane, B.D. (Eds.), 1995. Soil compaction and the environment. Soil Tillage Research 35, 1-113.
Vaz, C.M.P., Crestana, S., Mascarenhas, S., Cruvinel, P.E., Reichardt, K., Stolf, R., 1989. Using a computed tomography miniscanner for studying tillage induced soil compaction. Soil Technology 2, 313-321.

Vogel, H.J., 1997. Morphological determination of pore connectivity as a function of pore size using serial sections. European Journal of Soil Science 48, 365-377.

Voivret, C., Radjai, F., Delenne, J.-Y., El Youssoufi, M.S., 2007. Space-filling properties of polydisperse granular media. Physical Review E 76, 021301.

Voivret, C., Radjai, F., Delenne, J.-Y., El Youssoufi, M.S., 2009. Multiscale force networks in highly polydisperse granular media. Physical Review Letters 102, 178001.

Vulliet, L., Laloui, L., Schrefler, B., 2002. Environmental Geomechanics. EPFL Press, Lausanne.

Vyalov, S.S., 1986. Rheological Fundamentals of Soil Mechanics. Elsevier, Amsterdam, The Netherlands.

Wachs, A., 2009. A DEM-DLM/FD method for direct numerical simulation of particulate flows: sedimentation of polygonal isometric particles in a Newtonian fluid with collisions. Computation Fluids 38, 1608-1628.

Werner, D., Werner, B., 2001. Verdichtung und Regeneration des Gefüges eines schluffigen Tonbodens (Tschernosem): Bodenphysikalische, computertomographische und rasterelektronenmikroskopische Untersuchungen. Journal of Plant Nutrition and Soil Science 164, 79-90.

Wiermann, C., Werner, D., Horn, R., Rostek, J., Werner, B., 2000. Stress/strain processes in a structured unsaturated silty loam Luvisol under different tillage treatments in Germany. Soil Tillage Research 53, 117-128.

Zdravkovic, L., Carter, J., 2008. Contributions to Géotechnique 1948-2008: constitutive and numerical modelling. Géotechnique 58, 405-412.

Zienkiewicz, O.C., Taylor, R.L., 1994a. The Finite Element Method - Solid and Fluid Mechanics Dynamics and Non-linearity, 2. McGraw Hill, London, 807 pp.

Zienkiewicz, O.C., Taylor, R.L., 1994b. The Finite Element Method - Basic Formulation and Linear Problems, Vol. 1. McGraw Hill, London, 648 pp.

Zienkiewicz, O.C., Taylor, R.L., 2000. The Finite Element Method. McGraw-Hill, New York.

Zworykin, V.K., Ramberg, E.G., 1941. Surface studies with the electron microscope. Journal of Applied Physics 12, 692-695.

Zworykin, V.K., Hillier, J., Snyder, R.L., 1942. A scanning electron microscope. ASTM Bulletin 117, 15-23. 